Sílvia de Vincentiis

\title{
O estudo da função sexual e gonadal nas adolescentes com epilepsia
}

Dissertação apresentada à Faculdade de Medicina da Universidade de São Paulo para a obtenção do título de Mestre em Medicina.

Área de Concentração: Psiquiatria

Orientador: Dra. Kette Dualibi Ramos Valente

São Paulo 
Dedicatória 
Aos meus pais, Giuseppe e Eliane. 


\section{Agradecimentos especiais}

Este trabalho só foi possível graças à colaboração e ajuda das pacientes e seus familiares. 
Agradecimentos 
Agradeço a todos aqueles que diretamente ou indiretamente colaboraram para a realização deste projeto:

Meus pais e toda minha família, pelo apoio e incentivo incondicionais à minha carreira profissional e acadêmica.

Minha orientadora, Dra. Kette Dualibi Ramos Valente, pela seriedade, responsabilidade, carinho, amizade e paciência que sempre teve comigo. Por ser também uma das responsáveis por todo meu conhecimento em neurofisiologia clínica e por me ensinar absolutamente tudo desde o início sobre como escrever um trabalho científico.

Prof.Dr.Clóvis Artur Almeida da Silva, por ter tido a idéia inicial deste projeto e propiciado todas as condições para a realização do mesmo, além de ter dividido comigo todo o conhecimento acumulado através de muitos anos de dedicação à ciência.

Integrantes do Ambulatório de Adolescentes do Instituto da Criança do HCFMUSP, em especial à Profa. Dra. Maria Ignez Saito, por toda a orientação necessária para a avaliação das adolescentes e condução deste trabalho.

Integrantes do Ambulatório de Ginecologia da Adolescente do Instituto Central do HCFMUSP, em especial à Dra.Albertina Duarte Takiuti, pela orientação e avaliação das pacientes. 
Dra.Sílvia Maria Sucena da Rocha, do Serviço de Radiologia Pediátrica do ICrHCFMUSP, pela colaboração e orientação na realização deste projeto.

Dra. Marília Vieira Febrônio, do Serviço de Reumatologia do HCFMUSP, pela valiosa e imprescindível colaboração com este trabalho.

Dra.Lia Arno Fiore, pela contribuição e auxílio à realização deste projeto, através de idéias para sua execução, encaminhamento de pacientes, revisão da língua inglesa e, sobretudo, pronta disponibilidade para o que fosse preciso a qualquer momento. Por ser também, em conjunto com a Dra. Kette, responsável por todo meu conhecimento sobre neurofisiologia clínica e por ter a dose certa de descontração para que possamos realizar nosso trabalho com mais alegria.

Prof.Dr.Núbio Negrão, por dividir conosco conhecimentos de uma vida inteira dedicada à ciência.

Dra.Maria Sigride Thomé de Souza e Dr.Bernardo Barbosa Moreira, pela amizade e por terem levado adiante as obrigações assistenciais do Laboratório de Neurofisiologia Clínica enquanto estive afastada por conta deste projeto.

Patrícia Rzezak, pelo auxílio com as análises estatísticas, mesmo envolvida com seu próprio projeto. 
Dra.Stella Tavares, do Laboratório de Neurofisiologia Clínica do Instituto de Psiquiatria do HCFMUSP, pelas valiosas contribuições e sugestões.

Funcionários do Laboratório de Neurofisiologia Clínica, por sua ajuda de importância fundamental no recebimento das pacientes, coleta e encaminhamento de exames Erisvaldo, Vilson, Claudinha, Andreza, Lola, Amparo, Marly, Michele e Célia.

Dra.Alessandra Freitas, por toda a amizade e compreensão com que me brindou desde meu ingresso ao Laboratório de Neurofisiologia Clínica.

Sra.Eliza Fukushima, secretária da pós-graduação do programa de Psiquiatria da FMUSP. 


\section{LISTAS}

\section{RESUMO}

\section{SUMMARY}

Introdução

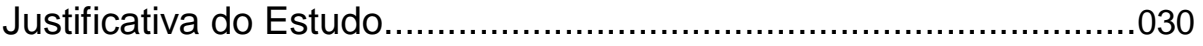

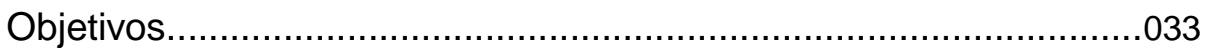

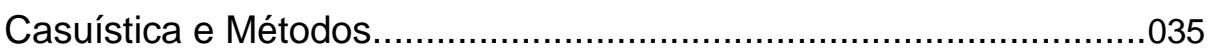

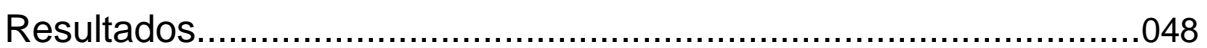

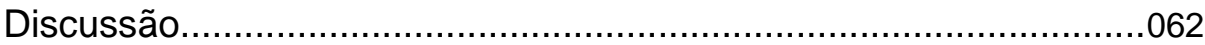

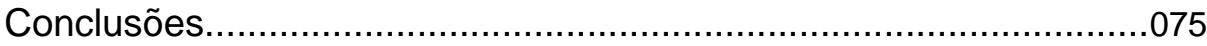

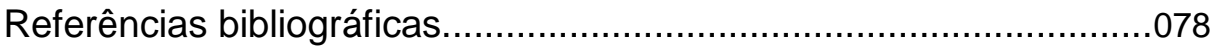

\section{ANEXOS}




\section{LISTA DE FIGURAS}

FIGURA 1 - Representação esquemática dos exames a serem realizados em um ciclo de 28 dias. .042

\section{LISTA DE QUADROS}

QUADRO 1 - Drogas usadas no tratamento das crises epilépticas em ordem alfabética....... 011

QUADRO 2 - Eficácia das novas DAE 012

QUADRO 3 - Complicações da gestação em mulheres com epilepsia .003 


\section{LISTA DE TABELAS}

TABELA 1 - Valores normais dos hormônios nas fases folicular e lútea. 044

TABELA 2 - Entrevistas realizadas e amostra final de pacientes .049

TABELA 3 - Características da epilepsia e da síndrome epiléptica em

35 pacientes .051

TABELA 4 - Tratamento medicamentoso da epilepsia em 35 pacientes. 052

TABELA 5 - Características do tratamento medicamentoso em 35 pacientes. .053

TABELA 6 - Controle de crises durante a gestação .057

TABELA 7 - Planejamento da gravidez e dados do recém-nascido .057

TABELA 8 - Função gonadal em 27 pacientes com epilepsia e avaliação conclusiva dos parâmetros metodológicos .060 
a: anos

BDZ: benzodiazepínico

CBZ: carbamazepina

CLB: clobazam

CLN: clonazepam

CPS: crises parciais simples

CPC: crises parciais complexas

DAE: droga(s) antiepiléptica(s)

DIU: dispositivo intra-uterino

DP: desvio padrão

DST: doenças sexualmente transmissíveis

E: esquerda

ELT: epilepsia do lobo temporal

EMT: esclerose mesial temporal

EEG: eletrencefalograma(s)

et al.: e outros

HIV: vírus da imunodeficiência humana

FBM: felbamato

FOP: falência ovariana precoce

FSH: hormônio folículo-estimulante

G: gestação

GBP: gabapentina

GnRH: hormônio liberador de gonadotrofinas

LESJ: lúpus eritematoso sistêmico juvenil

LEV: levetiracetam

LH: hormônio luteinizante 
LMT: lamotrigina

mio: mioclonia(s)

OXC: oxcarbazepina

PB: fenobarbital

PGB: pregabalina

PHT: fenitoína

PRM: primidona

RM: ressonância magnética

SNC: sistema nervoso central

SOP: síndrome dos ovários policísticos

Vídeo-EEG: vídeo-eletrencefalograma/ vídeo-eletrencefalografia

T3: triiodotironina

T4: tiroxina

T4 livre: tiroxina livre

TCG: crises tônico-clônicas

TCG $1^{\text {arias: }}$ crises tônico-clônicas primariamente generalizadas

TCG $2^{\text {arias }}$ : crises tônico-clônicas secundariamente generalizadas

TGB: tiagabina

TSH: hormônio tireo-estimulante

TPM: topiramato

USG: ultra-sonografia(s)

VGB: vigabatrina

VPA: valproato

ZNS: zonisamida 


\section{LISTA DE SÍMBOLOS}

$\%$ : por cento

=: igual a

dl: decilitro

L:litro

mg: miligramas

ml: mililitros

ng:nanogramas

pg: picogramas

UI: unidades internacionais

$\mu \mathrm{g}:$ microgramas

$\mu \mathrm{U}:$ microunidades

\section{LISTA DE SIGLAS}

CAPPesq: Comissão de Ética Médica para a Análise de Projetos de Pesquisa

FAPESP: Fundação de Amparo à Pesquisa do Estado de São Paulo

FMUSP: Faculdade de Medicina da Universidade de São Paulo

HC-FMUSP: Hospital das Clínicas da Faculdade de Medicina da Universidade de São Paulo

ICr: Instituto da Criança da Universidade de São Paulo

ILAE: International League Against Epilepsy (Liga Internacional Contra a Epilepsia)

IPq: Instituto de Psiquiatria da Universidade de São Paulo

SP: São Paulo

USP: Universidade de São Paulo 


\section{VINCENTIIS,SÍLVIA DE. O estudo da função sexual e gonadal nas}

adolescentes com epilepsia. São Paulo, 2008. Dissertação (mestrado) - Faculdade de Medicina da Universidade de São Paulo.

Em mulheres com epilepsia, sabe-se que a síndrome epiléptica, a freqüência de crises e as drogas antiepilépticas podem ter influência na função sexual, comportamento sexual e na capacidade reprodutora. Muitos fatores têm sido relacionados a estas alterações, tais como: duração e gravidade da epilepsia, tipo de droga antiepiléptica e localização da lesão epileptogênica. Baseado no conhecimento adquirido com as mulheres assume-se que as adolescentes sofram influência semelhante.

Este estudo teve como objetivo avaliar aspectos relacionados à função e ao comportamento sexual, à educação sexual e à função gonadal em adolescentes do sexo feminino com epilepsia. Para isso, foram estudadas prospectivamente 35 pacientes do sexo feminino, com epilepsia parcial e generalizada, com idades entre 10 a 20 anos, com epilepsia ativa, sendo o diagnóstico da síndrome epiléptica realizado segundo os critérios da Liga Internacional Contra a Epilepsia (1989). Os critérios de exclusão foram: ausência de menarca; uso de contraceptivo hormonal ou dispositivo intra-uterino, no momento da avaliação ou nos últimos três meses; antecedente de cirurgia ginecológica ou distúrbio endocrinológico; presença de doença crônica associada, ou deficiência mental moderada a grave que impossibilitassem o seguimento do protocolo a ser instituído.

As informações sobre a função sexual, comportamento sexual e a educação sexual das adolescentes com epilepsia foram avaliadas através de um questionário padrão. O protocolo de estudo da função gonadal incluiu a análise dos seguintes critérios: ciclo menstrual regular, presença de dismenorréia, dosagem dos níveis hormonais (FSH, LH, estradiol, progesterona, prolactina, testosterona, T3, T4 livre, 
TSH), ultra-sonografia pélvica, gestação em curso ou recente. A função gonadal foi considerada normal se pelo menos um ou mais parâmetros acima foi adequado.

Não foi observada diferença entre a idade da primeira relação sexual $(p=0,54)$, atividade sexual $(p=0,23)$, libido $(p=1,00)$ e orgasmo $(p=0,23)$ entre as adolescentes com epilepsia, em relação ao grupo controle. Todas as adolescentes sexualmente ativas relataram o uso de métodos contraceptivos, porém apenas 20,1\% com orientação de algum profissional de saúde. A idade da menarca nos dois grupos foi similar. No entanto, o uso de valproato próximo à menarca e crises freqüentes foram fatores antecipadores da menarca. As adolescentes com epilepsia apresentaram uma freqüência de ciclos menstruais irregulares superior à do grupo controle. A irregularidade menstrual relacionou-se com a presença de crises tônico-clônicas generalizadas $(p=0,02)$, sem relação com a síndrome epiléptica. Houve uma tendência a irregularidades menstruais em adolescentes que apresentavam duração da doença mais prolongada $(p=0,06)$, independente da freqüência de crises epilépticas. Observaram-se índices de gravidez superiores entre as adolescentes com epilepsia em comparação às controles $(p<.0001)$. Não houve diferença na freqüência de aborto entre as adolescentes com epilepsia.

Neste estudo, as adolescentes com epilepsia apresentaram comportamento e função sexual similares às adolescentes sem doenças crônicas. Embora a função gonadal destas pacientes estivesse preservada, os distúrbios menstruais foram significantes, sugerindo que estas adolescentes possam estar em um processo em evolução com ciclos anovulatórios e disfunção reprodutora na vida adulta. Portanto, os aspectos relacionados à função e comportamento sexual, contracepção e função gonadal, em adolescentes com epilepsia, requerem atenção especial por parte dos profissionais de saúde. 


\section{VINCENTIIS,SÍLVIA DE. Evaluation of sexual and gonadal function in}

female adolescents with epilepsy. São Paulo, 2008. Dissertação (mestrado) Faculdade de Medicina da Universidade de São Paulo.

It is known that in women with epilepsy, the epileptic syndrome, seizure frequency and antiepileptic drugs may act on sexual function, sexual behavior and reproductive function. Several factors have been associated with these changes such as: duration and severity of the epilepsy, kind of antiepileptic drug and locality of the epileptogenic lesion. Based on knowledge acquired with studies in women, it is assumed that female adolescents suffer similar influences.

This study aimed to evaluate several aspects related to sexual function, to sexual behavior, to sexual education and to gonadal function in female adolescents with epilepsy. We prospectively studied 35 females, with ages between 10 and 20 years, with active partial and generalized epilepsies and epileptic syndromes classified according to ILAE criteria (1989). Criteria of exclusion were: patients that had not yet had their menarche, those in use of hormonal contraceptives or intrauterine devices, either at the moment of the evaluation or in the last three months; patients with previous gynecological surgery or endocrine disorders; patients with associated chronic disease or moderate to severe mental deficiency that might hinder completion of the study protocol.

Information on sexual function and education were obtained with a standard questionnaire. Our study protocol for gonadal function included analysis of the following criteria: regular menstrual cycles, dysmenorrhea, hormonal levels (FSH, LH, stradiol, progesterone, prolactin, testosterone, T3, free T4, TSH), pelvic ultrasound study, and recent or ongoing pregnancy. Gonadal function was considered normal when at least one of the above parameters was found to be adequate. 
No significant differences were observed between age at first sexual intercourse $(p=0.54)$, sexual activity $(p=0.23)$, libido $(p=1,00)$ and orgasm $(p=0.23)$ among patients with epilepsy, when compared to controls. Sexually active adolescents reported the use of contraceptives, although only $20.1 \%$ with orientation done by a health professional. Age of menarche was similar in both groups, but the use of valproate close to menarche and frequent seizures were factors that anticipated this event. Moreover, adolescents with epilepsy presented irregular menstrual cycles more frequently than controls. Menstrual irregularity was correlated to the presence of tonicclonic generalized seizures $(p=0.02)$, regardless the epilepsy type or syndrome, and with longer disease duration $(p=0.06)$, despite of seizure frequency. Higher rates of pregnancy were observed in adolescents with epilepsy compared to controls $(p<.0001)$. Abortion rates were similar in both groups.

In this study, adolescents with epilepsy presented sexual function and behavior similar to their peers without chronic diseases. Although the gonadal function of these patients was spared, menstrual disorders were significant, suggesting that these adolescents may be in an ongoing process with anovulatory cycles and reproductive dysfunction in later adulthood. Therefore, aspects related to sexual behavior and function, contraception and gonadal function in adolescents with epilepsy require special attention by health professionals. 
Introdução 


\section{Epilepsia}

\subsection{Definição}

A epilepsia não é uma doença específica, ou mesmo uma síndrome única, mas uma condição composta por uma ampla categoria de sintomas complexos, tendo origem a partir de distúrbios do funcionamento cerebral, que por si só podem ser secundários a uma variedade de processos patológicos (Engel e Pedley, 1999). Portanto, a epilepsia é uma condição neurológica crônica, na qual a característica indispensável é a presença de crises epilépticas com a possibilidade de recorrência, que são tipicamente não provocadas e geralmente imprevisíveis (ILAE, 2001).

Uma crise epiléptica é o resultado de uma disfunção cerebral temporária, causada por uma descarga elétrica síncrona, anormal e auto-limitada de neurônios corticais. Há muitos tipos de crises epilépticas, cada uma delas com mudanças comportamentais características e distúrbios neurofisiológicos que, geralmente, podem ser detectados em registros com o eletrencefalograma (EEG) de superfície. As manifestações particulares de cada crise dependem de alguns fatores: se somente uma parte do córtex cerebral estiver envolvido no início, das funções das áreas corticais onde as crises têm origem, do padrão de espraiamento subseqüente da descarga elétrica ictal, e da extensão do envolvimento de estruturas subcorticais e do tronco cerebral (Pedley et al. 2000).

A crise epiléptica é um evento transitório, caracterizando-se como um sintoma da alteração da função cerebral. Embora as crises sejam a manifestação cardinal da epilepsia, nem toda crise implica em epilepsia. Por exemplo, as crises podem ser autolimitadas se ocorrem somente durante o curso de uma doença aguda e não persistem

após a resolução desta doença. Algumas pessoas, por razões desconhecidas, 
apresentam uma crise epiléptica única, não provocada. Tais eventos não representam epilepsia (Pedley et al., 2000).

Cada forma distinta de epilepsia tem sua própria história natural e resposta medicamentosa. Esta diversidade reflete o fato de que a epilepsia pode ser desencadeada por uma variedade de condições e mecanismos fisiopatológicos, embora a maioria dos casos seja classificada como "idiopática" ou "criptogênica" (Pedley et al., 2000).

\subsection{Classificação das crises e das síndromes epilépticas}

A classificação das crises epilépticas e das síndromes epilépticas é essencial para: a compreensão do fenômeno fisiopatológico, desenvolver um plano racional de investigação, tomar decisões sobre quando e por quanto tempo tratar, escolher a droga antiepiléptica (DAE) adequada, e conduzir investigações científicas (Pedley et al., 2000).

\subsubsection{Classificação das crises epilépticas}

A classificação usada hoje foi desenvolvida pela Liga Internacional Contra a Epilepsia (ILAE). Este sistema classifica as crises pelos sintomas clínicos, complementados pelos dados do EEG. 
Dois princípios fisiológicos importantes são inerentes à classificação. Em primeiro lugar, as crises epilépticas são fundamentalmente de dois tipos: aquelas com início limitado a parte de um hemisfério cerebral (crises parciais ou focais), e aquelas que parecem envolver o cérebro difusamente desde o início (crises generalizadas). Em segundo lugar, as crises epilépticas são dinâmicas e evoluem; a expressão clínica é determinada, em sua maior parte, pela seqüência do espraiamento da descarga elétrica no cérebro, bem como pela área onde a descarga ictal tem origem (Pedley et al., 2000).

As crises parciais e generalizadas são divididas em subtipos. Para as crises parciais, a subdivisão mais importante é baseada na consciência, que é preservada nas crises parciais simples (CPS) ou comprometida nas crises parciais complexas (CPC). As CPS podem evoluir para CPC, e ambas podem evoluir para crises secundariamente generalizadas. Em adultos, a maior parte das crises generalizadas tem início focal, mesmo que este não seja clinicamente aparente. Para crises generalizadas, as subdivisões são baseadas principalmente na presença ou ausência de manifestações motoras ictais (Pedley et al., 2000).

Os eventos iniciais de uma crise, descritos pelo paciente e/ou um observador, geralmente são a indicação clínica mais confiável para determinar se uma crise tem início focal ou generalizado (Pedley et al., 2000). Algumas vezes, entretanto, uma "assinatura" focal pode estar ausente por algumas razões:

1. O paciente pode apresentar amnésia após a crise, não se lembrando dos eventos iniciais;

2. A consciência pode ser comprometida ou a crise epiléptica tornar-se generalizada tão rapidamente, que a distinção de características iniciais pode ser obscurecida ou perdida;

3. A crise pode ter origem numa região do cérebro que não é associada com uma função comportamental clara; portanto, a crise epiléptica torna-se clinicamente 
evidente somente quando há espraiamento da descarga além da zona de início ictal ou quando se torna generalizada.

\section{Crises parciais}

As CPS ocorrem quando a descarga ictal se origina em uma área limitada e freqüentemente circunscrita do córtex, o foco epileptogênico. Os sintomas e fenômenos podem ser subjetivos (“aura”) ou manifestações observáveis, variando entre fenômenos motores elementares ("crises jacksonianas"; crises versivas) e alterações sensoriais unilaterais, até fenômenos dismnésticos, alucinatórios, emocionais e psíquicos complexos. Eventos especialmente comuns incluem: sensação epigástrica ascendente, medo, desrealização ou despersonalização, deja $v u$, jamais $v u$, e alucinações olfatórias. Os pacientes podem interagir normalmente com o ambiente durante as CPS, exceto pelas limitações impostas pela crise sobre funções cerebrais específicas (Pedley et al., 2000).

As CPC, por outro lado, são definidas pelo comprometimento da consciência e implicam em espraiamento bilateral da descarga epileptiforme. Em adição à perda de consciência, os pacientes geralmente apresentam automatismos, tais como deglutição, perseveração de funções motoras, ou outras atividades motoras complexas que são inapropriadas e não-direcionadas. Durante o período pós-ictal, os pacientes ficam confusos e desorientados por alguns minutos, e determinar a transição entre o estado ictal e pós-ictal pode ser difícil sem o registro eletrencefalográfico simultâneo. Nos adultos, aproximadamente $70 \%$ a $80 \%$ das CPC têm origem no lobo temporal (Pedley et al., 2000). 


\section{Crises generalizadas}

As crises tônico-clônicas generalizadas (TCG) são caracterizadas por perda abrupta da consciência, com extensão tônica bilateral do tronco e membros (fase tônica), freqüentemente acompanhada por vocalização (produzida pela passagem forçada de ar através das cordas vocais contraídas), seguida por abalos musculares síncronos (fase clônica). Em alguns pacientes, poucos abalos clônicos precedem a seqüência tônico-clônica; em outros, somente a fase tônica ou clônica é aparente. No pós-ictal, os pacientes permanecem letárgicos e confusos (Pedley et al., 2000).

As crises de ausência caracterizam-se por lapsos momentâneos do estado de alerta, acompanhados por parada da movimentação. Estas crises têm início e fim abruptos, ocorrendo sem alerta prévio ou período pós-ictal. Mioclonias leves das pálpebras ou músculos da face, perda variável do tônus muscular e automatismos podem acompanhar eventos mais prolongados. Quando o início ou fim da crise é menos súbito, ou se os componentes tônicos e autonômicos ocorrem simultaneamente, é utilizado o termo ausência atípica. Tais crises são mais freqüentemente encontradas em crianças com deficiência mental e epilepsia ou em encefalopatias epilépticas, tais como a síndrome de Lennox-Gastault (termo aplicado a um grupo heterogêneo de encefalopatias epilépticas da infância, caracterizado por deficiência mental, crises epilépticas refratárias e um padrão distinto ao EEG) (Pedley et al. 2000).

As crises mioclônicas são caracterizadas por abalos musculares breves e rápidos, que podem ocorrer bilateralmente, de maneira síncrona ou assíncrona, ou unilateral. As crises mioclônicas variam desde movimentos pequenos e isolados dos músculos da face, membros superiores ou membros inferiores, até espasmos bilaterais afetando simultaneamente o segmento cefálico, tronco e membros (Pedley et al., 2000). 
As crises atônicas (astáticas), também chamadas drop attacks, são caracterizadas por perda súbita do tônus muscular, que pode ser fragmentada (por exemplo, queda do segmento cefálico), ou generalizada, resultando em queda. Quando as crises atônicas são precedidas por uma crise mioclônica breve ou espasmo tônico, uma força de aceleração é adicionada à queda, contribuindo para as altas taxas de lesões provocadas por este tipo de crise (Pedley et al. 2000).

\subsubsection{Classificação das Síndromes Epilépticas}

A classificação da ILAE agrupa as epilepsias, em primeiro lugar, com base no início parcial (epilepsias relacionadas à localização) ou generalizado (epilepsias generalizadas) das crises epilépticas; em segundo lugar, pela causa (epilepsia idiopática, criptogênica ou sintomática). Os subtipos de epilepsias são agrupados de

acordo com a idade do paciente e, no caso das epilepsias relacionadas à localização, pela localização anatômica da zona provável de início ictal (ILAE, 1989).

\subsection{Epidemiologia}

Segundo os dados da Organização Mundial de Saúde (www.who.int/mental health/neurology/epilepsy) $5 \%$ da população mundial terá uma crise no decorrer de sua vida. Atualmente, acredita-se que haja 50 milhões de pessoas com epilepsia no mundo, $85 \%$ das quais vivendo nos países em desenvolvimento. Estima-se que 2.4 milhões de novos casos por ano ocorram todos os anos. Pelo menos $50 \%$ destes casos tem início da infância ou adolescência. $70 \%$ to $80 \%$ das 
pessoas com epilepsia podem levar uma vida normal se propriamente tratadas. Nos países em desenvolvimento, $60 \%$ a $90 \%$ das pessoas com epilepsia não recebem tratamento adequado do sistema de saúde devido ao estigma social da doença.

Há poucos estudos sobre a incidência de epilepsia na população. Nos países desenvolvidos, a incidência ajustada pela idade varia entre 24/100.000 a 53/100.000 pessoas por ano (Hauser WA, 1999). Alguns estudos mais recentes demonstraram que a incidência de epilepsia nos países em desenvolvimento é duas a três vezes mais alta do que nos países desenvolvidos, sendo, portanto consideravelmente superior (Hauser WA, 1999).

Corroborando o estudo de Hauser 1999, os dados da OMS demonstram que estudos em países desenvolvidos sugerem uma incidência anual de epilepsia de aproximadamente 50:100.000 da população em geral. Entretanto, estudos realizados nos países em desenvolvimento sugerem uma incidência anual de epilepsia de aproximadamente 100:100.000, duas vezes maior do que nos países em desenvolvimento. Uma das razões para a maior incidência de epilepsia nos países em desenvolvimento é o maior risco de ter uma condição que leve a um dano cerebral permanente. Estas condições incluem a neurocisticercose, meningite, malária, desnutrição e complicações pré e peri-natais. (www.who.int/mental health/neurology/epilepsy)

Há mais estudos demonstrando a prevalência da epilepsia nas diversas populações, por ser este dado mais facilmente obtido do que a incidência. A prevalência é uma medida da interação entre diversos fatores, tais como incidência, mortalidade, remissão da doença, migrações e acesso a serviços médicos. A prevalência é um reflexo da sobrevivência e gravidade da doença, mais do que apenas a freqüência da mesma (Hauser WA, 1999).

Os dados sobre prevalência podem variar de acordo com a metodologia utilizada, com índices entre 2,7/1000 a 40/1000 habitantes. Em países como Panamá, 
Equador, Venezuela e Colômbia, encontraram-se índices entre 14/1000 e 57/1000 (Hauser WA, 1999). Um estudo realizado na cidade de São Paulo, em 1986, demonstrou uma taxa de prevalência de 11,9/1000 habitantes (Marino et al.,1986). Outro estudo, realizado na cidade do Rio de Janeiro, demonstrou taxas de prevalência de 16,3/1000 habitantes, e de epilepsia ativa de 5,1 / 1000 (Gomes et al.,2002).

Em relação à prevalência, os dados da OMS (www.who.int/mental health/neurology/epilepsy) sugerem que a prevalência estimada de epilepsia ativa (crises persistentes ou necessidade de tratamento) é de aproximadamente 8.2 por 1.000 da população em geral. Entretanto, este valor pode estar subestimado como demonstrado em alguns estudos de países em desenvolvimento (Colômbia, Equador, Índia, Libéria, Nigéria, Panamá, Tanzânia e Venezuela) que sugerem uma prevalência superior a 10 por 1.000.

Portanto, é provável que aproximadamente 50 milhões de pessoas no mundo tenham epilepsia ao longo da sua vida A prevalência de epilepsia ao longo da vida, ou seja, o número de pessoas que tem, já tiveram epilepsia ou que terão epilepsia no futuro é de aproximadamente 100 milhões. (www.who.int/mental health/neurology/epilepsy)

\subsection{Tratamento}

O tratamento da epilepsia tem como objetivos eliminar as crises epilépticas ou reduzir sua freqüência ao mínimo possível, evitando os efeitos colaterais associados ao tratamento em longo prazo (Pedley et al.,2000).

A seleção de uma DAE apropriada começa com um diagnóstico acurado do tipo de crise, da epilepsia ou síndrome epiléptica. O primeiro passo é classificar o tipo 
de crise. O segundo passo é classificar o paciente segundo o tipo de epilepsia, se possível. Embora somente cerca de metade dos casos de epilepsia possam ser classificados como uma síndrome epiléptica, tentar fazê-lo é importante por diversas razões, principalmente por levar a um tratamento mais apropriado; também auxilia a evitar drogas que possam ser ineficazes ou aumentar a freqüência de crises. Por fim, conhecer o tipo de epilepsia tem implicações prognósticas significativas. Embora as DAE representem tratamentos sintomáticos, elas exibem certo grau de especificidade contra vários tipos de crises e de epilepsia. Em alguns casos, drogas que previnem um tipo de crise podem desencadear outro tipo, como no caso da carbamazepina, que pode causar a piora de crises mioclônicas. Os Quadros 1 e 2 mostram as principais DAE e sua principal indicação de uso no tratamento dos diferentes tipos de crises epilépticas (Dodson, 1999; Hitiris e Brodie, 2006). 
Quadro 1: Drogas usadas no tratamento das crises epilépticas em ordem alfabética (Adaptado de Dodson, 1999)

\begin{tabular}{|c|c|c|}
\hline $\begin{array}{c}\text { Crises parciais e tônico-clônicas } \\
\text { generalizadas }\end{array}$ & Crises de ausência & Crises mioclônicas \\
\hline $\begin{array}{l}\text { Carbamazepina } \\
\text { Clobazam } \\
\text { Felbamato } \\
\text { Lamotrigina } \\
\text { Oxcarbazepina } \\
\text { Fenobarbital } \\
\text { Fenitoína } \\
\text { Primidona } \\
\text { Tiagabina } \\
\text { Topiramato } \\
\text { Valproato } \\
\text { Vigabatrina } \\
\text { Zonisamida }\end{array}$ & $\begin{array}{l}\text { Acetazolamida } \\
\text { Clonazepam } \\
\text { Etosuximida } \\
\text { Valproato }\end{array}$ & $\begin{array}{l}\text { Acetazolamida } \\
\text { Clonazepam } \\
\text { Felbamato } \\
\text { Lamotrigina } \\
\text { Fenobarbital } \\
\text { Valproato } \\
\text { Vigabatrina }\end{array}$ \\
\hline
\end{tabular}


Quadro 2: Eficácia das novas DAE (Adaptado de Hitiris e Brodie, 2006)

\begin{tabular}{|c|c|c|c|c|c|c|c|c|c|c|}
\hline $\begin{array}{c}\text { Tipo de crise/ } \\
\text { síndrome }\end{array}$ & FBM & GBP & LEV & LMT & OXC & PGB & TGB & TPM & VGB & ZNS \\
\hline Parcial & E & E & E & E & E & E & E & E & E & E \\
TCG 2aria. & E & E & E & E & E & E & E & E & E & E \\
TCG 1aria & EP & EP & E & E & E & $?$ & $?$ & E & EP & E \\
Ausências & EP & --- & EP & E & -- & $?$ & -- & $?$ & -- & EP \\
Mioclonias & $?$ & --- & E & E & -- & $?$ & $?$ & E & --- & E \\
Lennox-Gastault & E & $?$ & $?$ & E & 0 & $?$ & $?$ & E & $?$ & $?$ \\
Espasmos infantis & $?$ & $?$ & $?$ & EP & 0 & $?$ & EP & EP & E & EP \\
\hline
\end{tabular}

E: eficácia comprovada; EP: eficácia provável;?: eficácia desconhecida;---:piora das crises; 0: ineficaz ; $E^{\text {a: }}$ LMT pode piorar crises mioclônicas em alguns casos; FBM: felbamato; GBP: gabapentina; LEV: levetiracetam; LMT: lamotrigina; OXC: oxcarbazepina; PGB: pregabalina; TCG 1aria : crises tônico-clônicas primariamente generalizadas; TCG 2aria : crises tônico-clônicas secundariamente generalizadas;TGB: tiagabina; TPM: topiramato; VGB: vigabatrina; ZNS: zonisamida 


\section{Função sexual e gonadal na mulher adulta com epilepsia}

\subsection{Sexualidade, Função Sexual e Comportamento Sexual}

A sexualidade humana é um termo amplo, que se refere a dimensões biológicas, psicológicas e sociais do ser humano. Ela é composta por domínios distintos, porém com estreita relação entre si - o desejo, a reprodução, e a interação entre os indivíduos (Beier, 2006).

A função sexual e o comportamento sexual compõem a sexualidade humana. Embora estes termos sejam usados como sinônimos, eles se referem a aspectos complementares, porém distintos da sexualidade. A função sexual humana é composta por três componentes essenciais, porém distintos: o desejo sexual (libido), a excitação sexual, e o orgasmo (Basson et al.,2000;Park et al.,1997). O comportamento sexual humano compreende atividades como a procura por parceiro ou parceiros, a interação entre indivíduos, a intimidade física ou emocional, e o contato sexual (http://en.wikipedia.org/wiki/Human sexual behavior).

\subsection{Função sexual na mulher com epilepsia}

Não há um consenso na literatura a respeito da freqüência de disfunção sexual em mulheres sem doença crônica e em idade fértil. Estimativas variam entre 19 a $50 \%$, dependendo da metodologia utilizada, das definições utilizadas para as disfunções, e da população estudada (Spector et al., 1990; Rosen et al., 1993; Laumann et al., 1999). 
Pacientes com epilepsia apresentam disfunção sexual com maior freqüência do que pacientes com outras doenças neurológicas (Morrell et al., 1998). Estima-se que disfunções do desejo e excitação sexual, incluindo dispareunia, vaginismo, e falta de lubrificação, afetem cerca de 30 a $60 \%$ das mulheres com epilepsia (Morrell et al.,2005).

A função sexual é mediada por múltiplas estruturas do sistema nervoso central, incluindo os lobos frontais, o córtex límbico e o hipotálamo, sendo que alterações estruturais ou funcionais destes locais podem causar disfunção sexual (Morrell et al., 1998). Estas áreas estão freqüentemente acometidas nas pacientes com epilepsia, provendo uma explicação estrutural para a correlação epilepsia-disfunção sexual.

Alterações neuroquímicas também podem estar implicadas nos distúrbios da esfera sexual. Elevações transitórias de neurotransmissores e neuropeptídeos podem produzir distúrbios no desejo sexual e excitação (Paredes et al.,1992; FernandezGuasti et al.,1989). A interferência das crises epilépticas sobre a liberação de hormônios do eixo hipotálamo-hipofisário pode levar a disfunção sexual de natureza endócrina, visto que os hormônios gonadais têm um papel importante na excitação e desejo sexual, tanto em homens quanto em mulheres (revisão em Morrell, 1998).

A disfunção sexual pode ainda ocorrer como um efeito adverso ao uso de DAE (Mattson et al.,1985). Em um estudo realizado por Morrell et al.,em 2005, 57 mulheres em idade reprodutiva, com epilepsia focal ou generalizada idiopática, e 17 controles, completaram questionários a respeito da sua experiência sexual, excitação, ansiedade, e sintomas apresentados, bem como um inventário de depressão. Uma avaliação endocrinológica foi realizada durante a fase folicular precoce do ciclo menstrual. Disfunção sexual foi mais comum em mulheres com epilepsia focal, em mulheres recebendo fenitoína (PHT), com baixos níveis de estradiol e sulfato de dehidro-epiandrosterona, e naquelas com sintomas auto-relatados de depressão, 
demonstrando que, embora os mecanismos de disfunção sexual sejam multifatoriais, a escolha da DAE parece ser um dos mecanismos que possa ser modificado.

Quanto aos aspectos psicológicos que podem estar relacionados aos distúrbios da esfera sexual, merece destaque o fato de que, embora a epilepsia não seja uma doença crônica visível, é uma doença estigmatizada e estigmatizante. Conseqüentemente, a inserção social destes pacientes muitas vezes é deficiente, e a baixa auto-estima decorrente das crises pode levar o indivíduo a sentir-se pouco atraente (Morrell, 2001). Ao contrário do se imaginava, em estudos realizados com crianças, o isolamento social é referido em fases precoces da vida (Duchowny et al.,1998). Portanto, a adolescente pode sofrer as conseqüências que o desajuste social acarreta em relação à sua função sexual precocemente.

\subsection{Função gonadal na mulher com epilepsia}

Embora na literatura os termos função gonadal e fertilidade sejam usados como sinônimos, a função gonadal refere-se à função ovulatória e endócrina dos ovários, que por sua vez é controlada pelo eixo hipotálamo-hipófise-gonadal. Os caracteres sexuais secundários, o aparecimento da menarca e o padrão menstrual são evidências clínicas de função ovariana adequada, e portanto de função gonadal preservada (Ferreira et al.,2001). Já o termo fertilidade corresponde a uma estimativa do número de crianças vivas nascidas de um casal (Souza, 2001).

Quanto à função gonadal, mulheres com epilepsia têm maior risco para desenvolver distúrbios menstruais do que mulheres na população geral. Segundo Herzog (2006), talvez uma em cada três mulheres com epilepsia possam ser afetadas, contra uma em sete na população geral. 
Até o momento, não há um consenso sobre qual o fator determinante (o tipo de epilepsia ou a terapêutica) que causa a disfunção gonadal. A síndrome epiléptica parece levar a alterações no funcionamento do eixo hipotálamo-hipofisário. O envolvimento de estruturas mesiais, como na epilepsia do lobo temporal, estaria mais relacionado a tal disfunção, devido à extensa interconexão entre o córtex límbico e o eixo hipotálamo-hipofisário. As crises epilépticas podem interromper tais conexões e alterar a liberação dos hormônios hipotalâmicos, que por sua vez alteram a liberação de FSH e LH, levando a mudanças na esteroidogênese e morfologia ovariana (Herzog, 2007; Morrell et al.,2004; Morrell et al.,2002; Herzog, 1996). Mulheres com crises epilépticas freqüentes também são mais predispostas a alterações menstruais (Herzog et al.,2005).

Estudos atuais em humanos e em modelos animais têm demonstrado uma implicação causal ou, ao menos, contribuitória da síndrome epiléptica, bem como das DAE, nas disfunções de natureza reprodutora (Tauboll, 2007; Herzog,2007; Herzog, 2006). A ação de ambas pode levar a modificações nos níveis dos hormônios sexuais e promover o desenvolvimento de desordens reprodutivas de natureza endócrina, especialmente de um fenótipo que lembra a síndrome dos ovários policísticos (Herzog,2007;Herzog, 2006). A síndrome dos ovários policísticos (SOP) caracteriza-se por anovulação crônica hiperandrogênica, manifestando-se através de alterações menstruais, ultra-sonográficas ou endócrinas. O hiperandrogenismo é representado por níveis séricos elevados de testosterona, androstenediona, ou de-hidro-epiandrosterona, em sua forma livre ou na forma conjugada sulfatada. O hirsutismo também é uma característica, porém sua manifestação pode variar consideravelmente conforme a etnia. A anovulação crônica é representada por:

(a) distúrbio menstrual (amenorréia, oligomenorréia, intervalos menstruais anormais, ou menometrorragia), freqüentemente por 
(b) evidência ultra-sonográfica de aumento do volume dos ovários, com múltiplos cistos foliculares e aumento do estroma ovariano, e

(c) níveis anormais de progesterona sérica durante a fase lútea. Entretanto, mulheres afetadas comumente apresentam reversão espontânea, apresentando ciclos ovulatórios (Herzog,2006; Herzog et al.,2001)

A SOP tem significância neurológica, metabólica e ginecológica. Muitos hormônios esteróides possuem propriedades neuroativas e psicoativas. O estrogênio, por exemplo, é pró-convulsivante e ansiogênico. A progesterona possui propriedades estabilizantes do humor, sedativas, hipnóticas, e inibidoras de crises epilépticas (Herzog,2006; Herzog et al.,2001).Os ciclos anovulatórios estão associados com um aumento de crises epilépticas, devido à exposição cerebral contínua ao estrógeno sem o efeito cíclico da progesterona. Além disso, como outros distúrbios endócrinos caracterizados por disfunção ovulatória, a SOP pode estar associada com uma freqüência maior de migrânea (Herzog,2006; Herzog et al.,2001). Do ponto de vista das repercussões ginecológicas, salienta-se o efeito desfigurante do hirsutismo, além da disfunção menstrual e ovulatória. O estrogênio tem sido associado com aumento nas taxas de câncer endometrial. Metabolicamente, a SOP é associada com resistência à insulina e dislipidemia, o que predispõe ao desenvolvimento de doença cardiovascular aterosclerótica e suas complicações (Herzog, 2006; Herzog et al.,2001). Na epilepsia do lobo temporal, independente do uso de DAE, 10 a $25 \%$ das pacientes apresentam um fenótipo que lembra a SOP (Herzog et al.,1986).

Um estudo realizado por Löfgren et al.,em 2006, com 148 mulheres com epilepsia, demonstrou que tanto a epilepsia generalizada idiopática quanto o uso de valproato (VPA) estiveram associados com um aumento na ocorrência de distúrbios reprodutivos de natureza endócrina, sobretudo se a epilepsia ou seu tratamento iniciaram-se em fases precoces da vida. 
Mulheres com epilepsia são mais susceptíveis a apresentarem alterações nos níveis de esteróides ovarianos. Esta disfunção periférica está predominantemente relacionada às DAE, e não à síndrome epiléptica (Morrell et al.,2001). As DAE indutoras enzimáticas levam a alterações do metabolismo dos esteróides sexuais (Murialdo et al.,1998) e aumento dos níveis séricos de proteínas carreadoras (Morrell et al.,2002). A carbamazepina (CBZ), a PHT e o fenobarbital (PB) induzem as enzimas do citocromo P450 e aumentam os níveis da globulina carreadora de hormônios sexuais, diminuindo os níveis de hormônios biodisponíveis (revisão em Morrell, 1996; Isojarvi et al.,2005; Isojarvi,2007).

O VPA inibe as enzimas do citocromo P450, aumentando a concentração dos androgênios. O excesso de androgênios circulantes em sua forma livre leva a virilização do fenótipo, hirsutismo e obesidade (Isojarvi,2007; Isojarvi et al., 1993; Murialdo et al.,1998; Pasquali et al.,1993; Deslypere et al., 1985; Devinsky et al.,2000; Biton et al.,2001). A obesidade, por sua vez, é relacionada à hiperestimulação dos ovários, com conseqüente hiperandrogenismo, ovários policísticos e alterações do ciclo menstrual (Pylvanen et al.,2006; Isojarvi et al.,1996; Morrell et al.,2002). A substituição do VPA por lamotrigina (LMT) resulta em uma diminuição no peso corporal e normalização dos níveis de testosterona, lipídios e insulina,por esta DAE não ter influência sobre as enzimas do citocromo P450 (Isojarvi et al.,1998 Morrell et al., 2001),

O risco para as alterações descritas acima, associadas ao VPA, parece ser mais alto quando o uso é iniciado durante a infância e adolescência (Herzog, 2006).

Em resumo, segundo Klein e Herzog, algumas explicações para os distúrbios endócrinos nas mulheres com epilepsia são as seguintes:

influência direta da lesão epileptogênica (principalmente nas lesões das estruturas mesiais), epilepsia, ou DAE nos centros de controle endócrino do cérebro (eixo hipotálamo-hipofisário). 
os efeitos das DAE no metabolismo de hormônios e proteínas de

ligação

complicações endócrinas secundárias a alterações de peso ou resistência à insulina relacionada às DAE

Portanto, as funções sexual e reprodutora feminina são influenciadas por múltiplos fatores: a epilepsia ou síndrome epiléptica, o controle de crises, a terapêutica instituída e a interação entre eles.

\subsection{Contracepção, gestação e parto}

Em mulheres que recebem DAE indutoras enzimáticas, há um maior risco de falha dos contraceptivos esteróides orais, chegando a índices superiores a $6 \%$ quando da utilização de anticoncepcionais de baixa dosagem hormonal (Foldvary, 2001).

Complicações obstétricas ocorrem freqüentemente em mulheres com epilepsia. O risco de aborto espontâneo em mulheres com epilepsia é quatro vezes maior do que na população geral (Schupf et al.,1997).

Aproximadamente $25 \%$ das mulheres irão apresentar um aumento no número de crises durante a gestação. A causa é multifatorial e envolve baixa aderência às medicações, diminuição dos níveis de DAE devido a modificações na absorção e metabolismo, privação de sono e estresse (Liporace et al.,2003). As crises tônicoclônicas generalizadas são danosas para o feto em desenvolvimento, causando hipóxia, elevação dos níveis pressóricos maternos e alterações eletrolíticas, podendo também estar associadas ao abortamento espontâneo e à morte intra-uterina devido a traumas secundários decorrentes das crises epilépticas (Liporace et al.,2003).

O trabalho de parto e o nascimento, na maioria dos casos, evoluem sem intercorrências, embora nos países desenvolvidos, a indução do trabalho de parto e parto cesariana ocorram pelo menos duas vezes mais que na população geral 
(Foldvary, 2001). A incidência de mortalidade perinatal é duas vezes maior entre crianças de mães com epilepsia (Foldvary, 2001). O Quadro 3 mostra as complicações obstétricas mais freqüentes em mulheres com epilepsia e os efeitos sobre o produto conceptual. 
Quadro 3: Complicações da gestação em mulheres com epilepsia (adaptada de Yerby et al.,1997).

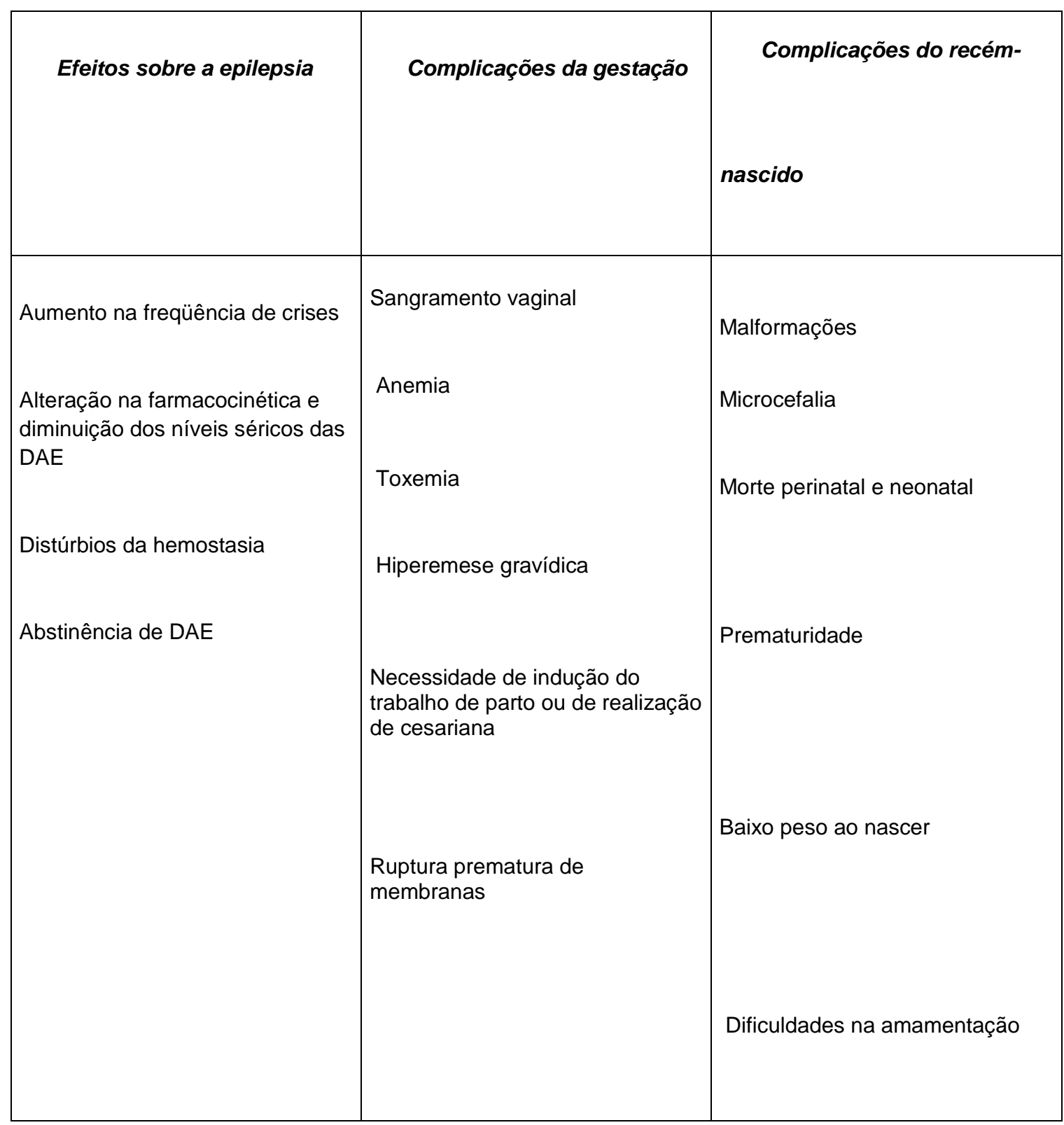


A gestação em mulheres com epilepsia não deve ser desestimulada, porém o aconselhamento precoce e individualizado sobre anticoncepção e gestação é essencial. A gestação deve ser planejada, com uso prévio à gravidez de ácido fólico, e o tratamento da epilepsia reavaliado, com a utilização da menor dose efetiva de DAE e em monoterapia quando possível. A monitorização fetal deve incluir ultra-sonografia obstétrica de alta resolução antes da vigésima semana e mensuração dos níveis de alfa-fetoproteína. A amniocentese não deve ser realizada rotineiramente. A dosagem dos níveis séricos de DAE pode ser útil para garantir que a menor dose eficaz está sendo utilizada, sobretudo para as DAE cuja farmacocinética se altera durante a gravidez. A amamentação deve ser estimulada, qualquer que seja o tratamento ministrado à mãe (Tettenborn, 2006).

\subsection{Teratogenia}

Malformações congênitas maiores ocorrem em 4 a $8 \%$ dos filhos de mulheres com epilepsia, representando o dobro dos índices de ocorrência da população geral (Foldvary, 2001). Malformações maiores são decorrentes de defeitos estruturais durante a organogênese que resultam em disfunção significativa. As malformações mais comuns incluem defeitos do tubo neural, cardiopatias congênitas, fendas orofaciais, atresia intestinal e defeitos urogenitais. A incidência é maior nos filhos de mulheres tratadas com DAE, porém também é aumentada em mulheres não tratadas e filhos de homens com epilepsia (Foldvary, 2001). Tais malformações são associadas com todas as DAE de primeira linha: CBZ,PB, PHT,VPA e primidona (PRM).

Malformações menores são caracterizadas por desvios do desenvolvimento normal que não resultam em conseqüências sérias do ponto de vista clínico ou cosmético. Estas incluem dismorfismos crânio-faciais, hipoplasia digital distal ou ungueal, anormalidades esqueléticas menores e hérnias umbilicais e inguinais. Tais 
alterações são observadas em 20 a $30 \%$ dos filhos de pais com epilepsia, representando um índice duas a três vezes superior ao da população geral (Foldvary, 2001). Contudo, deve-se salientar o fato de que muitos estudos possuem desenho prospectivo inadequado, amostra de tamanho insuficiente, tempo inadequado de seguimento (muitas anormalidades não são detectáveis ao nascimento), descrição inadequada das anomalias ou variações na maneira de classificá-las (Perucca,2005).

Não há, até o momento, estudos com metodologia adequada sobre os efeitos teratogênicos das DAE de nova geração. A DAE de nova geração com mais dados disponíveis atualmente é a LMT. Registros internacionais sugerem que o risco de malformações associado a doses superiores a $200 \mathrm{mg} / \mathrm{dia}$ de LMT é similar ao do VPA em doses superiores a 1000mg/dia (Perucca,2005).

\subsection{Falência ovariana precoce}

A falência ovariana precoce (FOP), definida clinicamente pela ocorrência da menopausa antes dos 40-45 anos, ocorre numa freqüência de $1 \%$ na população geral (Klein et al.,2001). Estudos prévios do efeito hormonal sobre o controle de crises em mulheres com epilepsia sugerem que a FOP possa ocorrer em uma freqüência maior nesse grupo (Klein et al.,2001).

O estudo de Klein et al., em 2001, avaliou 50 mulheres com epilepsia, entre 38 e 64 anos, com início de crises epilépticas antes dos 41 anos. Menopausa prematura não-cirúrgica foi definida como amenorréia secundária com duração superior a 12 meses, com níveis de FSH superior a 14 Unidades Internacionais (UI) nas mulheres com idade inferior a 42 anos. Perimenopausa prematura foi definida pela presença de um ou mais dos sintomas seguintes: sintomas perimenopausa somáticos; mudança no intervalo dos ciclos, previamente regulares, sem evidência de outros distúrbios endocrinológicos; e níveis de FSH superiores a 14 UI ou níveis de inibina $\mathrm{A}$ abaixo de 
$7 \mathrm{pg} / \mathrm{ml}$. Sete (14\%) das 50 mulheres com epilepsia apresentaram perimenopausa prematura não-cirúrgica (seis das sete) ou menopausa (uma de sete). Não houve correlação estatisticamente significante entre as mulheres com e sem FOP quanto à duração da epilepsia, idade de início, gravidade, lateralização, história de tabagismo, idade da menarca, índice de massa corpórea e incidência de depressão. Não houve associação entre a ocorrência de FOP e DAE. Já no estudo de Tran (2006), os principais fatores de risco encontrados para a ocorrência de FOP foram crises de início precoce e a persistência de crises recorrentes durante a idade adulta. Tais dados sugerem, portanto, que mulheres com epilepsia possam apresentar um comprometimento precoce de sua função reprodutora.

\section{Epilepsia e função gonadal na adolescente}

\subsection{O impacto das doenças crônicas no adolescente}

A adolescência é um período marcado pela puberdade, a procura por novidades, identificação social e sexual e consolidação de traços de personalidade (Devinsky et al.,1999).

$\mathrm{Na}$ revisão realizada por Devinsky et al., em 1999, verificou-se que adolescentes com epilepsia apresentam com maior freqüência distúrbios de comportamento comparado aos controles saudáveis ou com asma; expressam um maior número de preocupações e participam menos de atividades esportivas competitivas. O estudo de Wong et al.,em 2006, corrobora este dado, demonstrando que adolescentes com epilepsia praticam menos esportes e participam menos em esportes competitivos, com conseqüências físicas, como tendência a sobrepeso e obesidade. Duas das principais preocupações que surgem nesta faixa etária são o 
receio de não poderem tornar-se pais ou terem pior desempenho no mercado de trabalho (Devinsky et al.,1999).

Devido à maior conscientização em relação à doença, a abordagem deveria ser diferente do que a anteriormente proporcionada na infância, que visa predominantemente o controle das crises epilépticas e a redução dos efeitos colaterais das DAE, baseada na opinião dos pais e do profissional de saúde envolvido. Aparentemente, as expectativas de pacientes, pais e médicos são distintas na adolescência (Slevin et al.,1988). O conceito de freqüência de crises "aceitável" da epilepsia difere entre os três grupos de pessoas envolvidos (profissionais de saúde, pais e pacientes). Esta discrepância fica ainda maior quando se analisam as esferas sociais, emocionais e acadêmicas (Devinsky et al.,1999).

Apesar de a adolescência representar um período único, nota-se a falta de estudos sobre adolescentes com doenças crônicas, em especial adolescentes com epilepsia que abordem de forma direta, os diferentes aspectos próprios desta fase, como a função sexual, o comportamento sexual e a função reprodutora. Os estudos existentes com adolescentes com epilepsia são direcionados para a investigação das síndromes epilépticas ou para os aspectos psicológicos e filosóficos desta faixa etária.

\subsection{Qualidade de vida em adolescentes com epilepsia}

Crianças e adolescentes com epilepsia têm pior qualidade de vida, mesmo quando têm as crises controladas (Lach et al.,2006), embora o estudo de Stevanovic, em 2007, tenha demonstrado que adolescentes com bom controle de crises avaliaram sua qualidade de vida como satisfatória.

Dentre os inúmeros fatores que influenciam um melhor ou pior desempenho nos questionários de qualidade de vida de adolescentes com epilepsia, ressalta-se o sexo do paciente. Austin et al.,em 1996, verificaram que adolescentes do sexo 
feminino apresentavam pior escore nos questionários de qualidade de vida, o que foi corroborado posteriormente por Devinsky et al.,em 1999. Enquanto as adolescentes com epilepsia apresentam uma maior percepção da doença, menor auto-estima e insatisfação com a imagem corporal (Bagley et al.,1997; Hagborg 1993; Sweeting 1995), os adolescentes com epilepsia apresentam uma maior negação da sua doença (Van der Lugt, 1975).

Lee et al.,em 2006, realizaram um estudo em um grupo selecionado de 28 adolescentes com epilepsia grave e refratária em monitorização vídeoeletrencefalográfica para cirurgia de epilepsia. Pacientes e seus pais responderam a um questionário sobre qualidade de vida. $\mathrm{O}$ escore dado pelos pais foi pior que 0 escore dado pelos próprios adolescentes, sendo esta diferença estatisticamente significante para estigma, desempenho escolar, concentração e memória, e impacto da epilepsia. Os autores postulam que tal discrepância ocorra por uma tendência a minimizar ou negar tais problemas por parte dos adolescentes, como demonstrado por Van der Lugt, em 1975, para os adolescentes do sexo masculino com epilepsia.

\subsection{A função e o comportamento sexual na adolescente com epilepsia}

$\mathrm{Na}$ adolescente com epilepsia, o conhecimento a respeito da função e do comportamento sexual é, na sua maior parte, extrapolado do conhecimento dos efeitos da epilepsia na mulher, descritos na fase adulta (revisão em Vincentiis et al.,2004). Portanto, concebe-se que a adolescente apresente uma diminuição da libido comparada a adolescentes da mesma idade, como observada na mulher com epilepsia (Morrell et al.,2001; Morrell et al.,1994; Morrell et al.,1996; Wallace et al.,1998).

Em relação ao comportamento sexual, alguns estudos mostraram que os adolescentes com doenças crônicas têm vida sexual ativa (Silva et al.,2001; Carroll et 
al.,1983; Suris et al.,1996; Choquet et al.,1997). Em um dos maiores estudos populacionais, realizado por Suris et al.,em Minnesota, durante o ano letivo de 19861987, com 36.284 adolescentes categorizados em três grupos (doenças crônicas visíveis, doenças crônicas não-visíveis e controles) verificou-se que não houve diferença na idade da primeira relação sexual, na freqüência da atividade sexual, uso de contracepção e história de gravidez. Outra constatação foi a de que adolescentes com doenças crônicas apresentavam doenças sexualmente transmissíveis (DST) com maior freqüência, dado estatisticamente significativo. Em concordância com o estudo de Suris et al., outro estudo realizado na França por Choquet et al. em 1997, com uma série menor (7936 adolescentes) demonstrou que pacientes com doenças crônicas não só apresentavam vida sexual ativa, como esta era mais freqüente do que no grupo controle idade-pareado. Por outro lado, Carroll et al., em 1983, relataram que, apesar de adolescentes com doenças crônicas terem vida sexual ativa, estes não eram instruídos sobre opções de contracepção ou sexualidade em geral, pelos seus médicos, um dado inesperado, visto que estes adolescentes têm maior contato com profissionais da área de saúde do que pacientes saudáveis. Este achado parece justificar a freqüência maior de DST neste grupo de pacientes (Suris et al.,1996).

$\mathrm{Na}$ revisão de Neinstein (2001) observou-se que, por desconhecimento, os profissionais de saúde freqüentemente negligenciam aspectos da sexualidade e capacidade reprodutora dos jovens com doença crônica, muitas vezes por não estarem preparados para esta tarefa, assumindo que esta não é uma preocupação desta faixa etária.

Assim sendo, o adolescente com doença crônica está exposto à mesma série de comportamentos que são inerentes a esta fase da vida, e que caracterizam, em sua maior parte, a transição da infância para a vida adulta (Jessor, 1991). 
Um dos maiores problemas dos estudos citados acima é a abordagem de condições nosológicas diferentes que provavelmente têm impactos distintos sobre a função e o comportamento sexual.

\subsection{Função gonadal na adolescente com epilepsia}

Não sabemos, até o momento, se a função gonadal na adolescente com epilepsia está comprometida. Sabe-se que mulheres com epilepsia apresentam um maior número de ciclos anovulatórios, demonstrando uma função gonadal inadequada (Morrell et al.,2002). O estudo de Mikkonen et al., em 2004, com 69 crianças e adolescentes com epilepsia, entre oito e 18 anos, demonstrou que a função reprodutora não era comprometida nas pacientes que descontinuavam o uso de DAE antes da idade adulta; porém, há um aumento na prevalência de distúrbios endocrinológicos nas pacientes que permanecem após a idade adulta em uso de DAE (Mikkonen et al.,2004).

Um estudo sobre qualidade de vida de adolescentes com epilepsia (Devinsky et al.,1999), mostrou que os adolescentes com epilepsia têm preocupação quanto à sua capacidade em gerar filhos. Portanto, faz-se necessário estudar a função gonadal nas adolescentes com epilepsia de forma individualizada, para conduzir uma gestação e parto saudáveis, e orientar o exercício da sexualidade. Detectando a disfunção gonadal precocemente, pode-se ainda orientar uma melhor terapêutica medicamentosa, visando melhorar a função gonadal na vida adulta (Vincentiis et al.,2004).

A importância do estudo da função gonadal no adolescente pode ser demonstrada no estudo de Silva et al. (2002) com adolescentes com lúpus eritematoso sistêmico, que embora tivessem atividade sexual normal, apresentavam anormalidades na análise do sêmen caracterizadas por azoospermia, 
oligoastenoteratospermia e teratospermia, que provavelmente comprometerão sua função reprodutora na vida adulta. Conseqüentemente, a criação de um banco de esperma para estes pacientes passa a ser imperativa. Há evidências de que estes dados sejam reprodutíveis para a população com epilepsia. O estudo epidemiológico conduzido no Reino Unido por Wallace et al., em 1998, onde a função gonadal foi mensurada pela capacidade de reprodução (gestação) mostrou que mulheres com epilepsia tratada (em uso de DAE) apresentavam taxas de gestação estatisticamente menor comparadas à taxa nacional pareada por idade. A diferença foi estatisticamente maior na vida adulta, ou seja, em mulheres com 25 a 39 anos, demonstrando uma redução nas taxas de gestação idade-relacionada. Tais dados foram corroborados pelo estudo realizado por Artama et al.,na Finlândia, em 2006. Demonstra-se, desta forma, a necessidade do estudo da função gonadal na adolescência para que se possa identificar e prevenir causas potencialmente tratáveis de disfunção gonadal. 
Justificativa do Estudo 
Há uma necessidade premente de uma melhor compreensão do impacto das doenças crônicas nas diferentes esferas da adolescência. Apesar dos inúmeros estudos sobre o binômio função gonadal-função sexual e sua relação com a epilepsia e as DAE nas mulheres, há poucos estudos sobre a função sexual e gonadal nas adolescentes com doenças crônicas, incluindo as pacientes com epilepsia.

É na adolescência que o paciente começa a conviver com a doença, ou porque começa a manifestar os sintomas nesta época, ou porque começa a ter uma melhor compreensão das restrições da doença, mesmo tendo recebido o diagnóstico desde a infância. Nesta faixa etária, a adolescente passa a ter consciência da sua sexualidade e passa a exercê-la em seus diferentes aspectos.

Em adultos, sabe-se que a síndrome epiléptica e a freqüência de crises, assim como as DAE, têm influência na capacidade reprodutora. Na epilepsia do lobo temporal (ELT), dada a proximidade das estruturas mesiais com o eixo hipotálamohipofisário, há interferência na liberação hormonal. Postula-se que nas epilepsias generalizadas, a influência da terapêutica instituída possa assumir papel preponderante sobre as alterações da função reprodutora observadas. É difícil avaliar separadamente a influência exercida pela síndrome epiléptica e pela DAE, pois existem tratamentos de primeira escolha distintos para cada uma destas síndromes: CBZ para a ELT e VPA para as epilepsias generalizadas.

Supõe-se, até o momento, que alterações que dizem respeito aos aspectos da função sexual e da função reprodutora ocorram também com as adolescentes com epilepsia, que não têm evolução prolongada da doença e uso crônico de DAE, pressupondo-se que estas também apresentem diminuição da libido, maior freqüência de ciclos anovulatórios e, portanto, maiores índices de disfunção gonadal. Conseqüentemente, a adolescente com epilepsia em uso de DAE experimenta várias conseqüências do exercício não orientado da sua sexualidade, dentre elas, uma gestação não planejada, com risco de teratogenicidade e piora das crises epilépticas. 
Portanto, o estudo da função gonadal nas adolescentes com epilepsia é mandatório devido à necessidade de atenção e orientação dirigidas para essa faixa etária. A orientação adequada e individualizada a essas pacientes abrange aspectos relacionados à terapêutica, exercício da sexualidade (orientação, contracepção e proteção contra doenças sexualmente transmissíveis), gravidez, parto e prevenção de teratogenia. 
Objetivos 


\section{Geral}

O objetivo deste estudo foi avaliar aspectos da função sexual, do comportamento sexual, da educação sexual e da função gonadal em um grupo de adolescentes do sexo feminino com epilepsia.

\section{Específicos}

1. Determinar o comportamento e a função sexual de um grupo de adolescentes do sexo feminino com epilepsia e compará-lo com um grupo de adolescentes do sexo feminino sem doença crônica;

2. Estudar a função gonadal em um grupo de adolescentes com epilepsia;

3. Avaliar se adolescentes com epilepsia recebem orientação e qual o tipo de orientação recebida quanto à vida sexual, contracepção, gestação e parto e;

4. Comparar variáveis do comportamento sexual, função sexual, função gonadal e educação sexual com variáveis clínicas da epilepsia. 


\section{Caracterização da população a ser estudada}

\section{Pacientes}

As pacientes foram recrutadas do Ambulatório de Epilepsia do Instituto de Psiquiatria do Hospital das Clínicas da Faculdade de Medicina da Universidade de São Paulo, centro terciário de diagnóstico e tratamento. Para todas as pacientes e familiares foi explicado, pessoalmente, as etapas da pesquisa e os seus objetivos, informando-os sobre a escassez de dados na literatura médica nesta faixa etária.

O consentimento informado e esclarecido foi obtido de todas as pacientes e/ou responsáveis para a participação no estudo (Anexo I). A pesquisa foi aprovada pela Comissão de Ética para Análise de Projetos de Pesquisa - CAPPesq da Diretoria Clínica do Hospital das Clínicas e da Faculdade de Medicina da Universidade de São Paulo.

Para este estudo, os critérios de inclusão foram:

1. Pacientes do sexo feminino

2. Adolescentes com idades entre 10 a 20 anos

3. Pacientes com epilepsia ativa, ou seja, pacientes que apresentaram crises epilépticas nos últimos cinco anos ou em uso de DAE

4. Pacientes com o diagnóstico de epilepsia, classificadas segundo os Critérios da Liga Internacional Contra Epilepsia (ILAE, 1989).

5. Presença de Menarca

Os critérios de exclusão foram:

1. Pacientes com história pregressa de epilepsia, mas que estavam sem crises epilépticas há mais de cinco anos e que não estivessem em uso de DAE 
2. Uso de método contraceptivo hormonal no momento da avaliação ou nos últimos três meses e uso de dispositivo intra-uterino

3. História pregressa de cirurgia ginecológica ou distúrbio endocrinológico

4. Pacientes com deficiência mental moderada a grave, que impossibilitassem o seguimento do protocolo a ser instituído

5. Presença de outra doença crônica maior associada, incluindo transtornos psiquiátricos maiores

\section{Controles}

O grupo controle foi composto por 35 adolescentes sem doença crônica, sexo e idade-pareado, provenientes do ambulatório de Ginecologia da Adolescente do Hospital das Clínicas da FMUSP.

\section{Caracterização dos critérios metodológicos}

\subsection{Protocolo para diagnóstico e classificação da síndrome epiléptica}

Todas as pacientes incluídas neste estudo foram provenientes do Ambulatório de Epilepsia do Instituto e Departamento de Psiquiatria ou avaliadas segundo protocolo padrão de atendimento deste ambulatório, portanto tiveram diagnóstico estabelecido de epilepsia.

\section{Epilepsias generalizadas}

Pacientes com epilepsia generalizada sintomática foram excluídas, pelo seu comprometimento cognitivo, fator limitante para a obtenção de informações fidedignas. 
Avaliação Clínica: As pacientes apresentaram quadro clínico característico de epilepsia generalizada idiopática. A síndrome epiléptica foi determinada segundo o tipo de crise predominante. Por exemplo, as adolescentes com crises mioclônicas, como o tipo predominante de crise, foram classificadas como pacientes com epilepsia mioclônica juvenil.

Estudo Neurofisiológico (EEG): Apresentaram complexos irregulares de multiespícula-onda lenta $(4 \mathrm{a} 6 \mathrm{~Hz}$ ) ou complexo espícula-onda $(3-3,5 \mathrm{~Hz})$ no momento do estudo ou em EEG anteriores.

Portanto, foram consideradas as pacientes que apresentavam crises epilépticas generalizadas (mioclonias, tônico-clônica generalizada e ausência típica) com estudo neurofisiológico em algum momento da sua evolução compatível com este diagnóstico.

\section{Epilepsias parciais}

Avaliação Clínica: As pacientes foram entrevistadas com questionário padrão utilizado na rotina do Ambulatório de Epilepsia. A análise retrospectiva de prontuários foi realizada sempre que necessário.

As pacientes com epilepsia parcial criptogênica tiveram suas crises documentadas através de vídeo-EEG, quando apresentavam crises freqüentes. $O$ vídeo-EEG foi utilizado por ser este considerado como um método padrão para o estudo semiológico das crises epilépticas.

Pacientes que já estavam controlados com DAE e que não necessitassem de maior elucidação semiológica, sendo possível a determinação do tipo de crise epiléptica através dos dados da história, não foram submetidas a este procedimento.

Estudo por RM: Todas as pacientes com epilepsia parcial, exceto as idiopáticas, foram submetidas a exame de RM. Pacientes sem lesão à RM foram tidas como criptogênicas ou provavelmente sintomáticas e realizaram vídeo-EEG para a localização da zona epileptogênica. 
Estudos Neurofisiológicos (EEG e/ou V-EEG): Todas as pacientes tiveram EEG localizatório e lateralizatório. As pacientes que apresentaram EEG interictal duvidoso foram submetidas ao vídeo-EEG para registro de crises.

Portanto, para que se estabelecesse o diagnóstico de epilepsia parcial sintomática ou criptogênica, a paciente apresentou:

1. História; EEG e RM compatíveis.

2. Se RM normal com história e EEG compatíveis - V-EEG demonstrando zona de início ictal ou

3. Se EEG duvidoso com história e RM compatíveis - V-EEG demonstrando zona de início ictal ou

4. Se a semiologia de crises duvidosa com EEG e RM compatíveis - VEEG demonstrando zona de início ictal

\subsection{Metodologia para a avaliação da função e do comportamento} sexual

A metodologia para a avaliação da função sexual e gonadal foi desenvolvida em colaboração com a Unidade de Adolescentes (Prof ${ }^{a}$. Dr ${ }^{a}$. Maria Ignez Saito) e de Reumatologia Infantil (Dr. Clóvis Artur Almeida da Silva) do Instituto da Criança do Hospital das Clínicas da FMUSP, já tendo sido anteriormente realizada para um grupo de adolescentes normais e adolescentes com lúpus eritematoso sistêmico,em uma população brasileira (Silva et al.,2002).

O comportamento, a função e a educação sexual recebida pelas adolescentes foram avaliados através de questionário pré-estruturado (Anexo II). Este questionário consistiu de quatro partes, as três primeiras com informações obtidas através de entrevista e a quarta parte através de auto-preenchimento. As informações contidas neste formulário e referentes ao comportamento sexual (quarta parte) foram 
confidenciais para a proteção da adolescente. Embora a maior parte das pacientes incluídas tivesse idade inferior a 18 anos, tais informações não foram compartilhadas com os pais e responsáveis. Somente participaram as adolescentes cujos pais compreendessem a natureza deste item.

A primeira parte do questionário foi composta por dados pessoais (classe socioeconômica, idade, escolaridade) e dados referentes à epilepsia (idade de início, duração, tipo de crises, síndrome epiléptica, controle no momento da avaliação, tratamento atual e prévio).

A segunda parte, referente à história ginecológica e obstétrica, foi composta por: idade da menarca, ciclos menstruais (intervalo e duração), dismenorréia, gestações, abortos, parto e dados do recém-nascido.

A terceira parte relativa à educação sexual recebida pelas pacientes, foi constituída por questões sobre a orientação (profissional ou de outras fontes) sobre anticoncepção, doenças sexualmente transmissíveis, uso de preservativo nas relações, uso de ácido fólico, orientação sobre gestação em mulheres com epilepsia, planejamento de gravidez.

A quarta parte consistiu em um questionário auto-aplicado, onde as pacientes responderam a perguntas sobre comportamento sexual: masturbação, início da atividade sexual, libido, orgasmo, número de parceiros no último ano e freqüência de relações sexuais. 


\subsection{Metodologia para a avaliação da função gonadal}

\subsubsection{Avaliação ginecológica}

Foi realizada uma avaliação ginecológica prévia, com ênfase na anamnese, exame físico da genitália e realização de exames complementares. As avaliações foram realizadas pelo Ambulatório de Ginecologia da Adolescente da FMUSP (sob a supervisão da Dra. Albertina Duarte Takiuti).

\subsubsection{Parâmetros clínicos e laboratoriais adotados}

As pacientes foram orientadas a realizar calendário dos ciclos menstruais por três meses. A partir de uma comunicação por telefone sobre a ocorrência do primeiro dia da menstruação, as pacientes foram submetidas aos exames complementares e ao exame ginecológico.

Entre $\circ 2^{\circ}$ e $3^{\circ}$ dia do ciclo menstrual (fase folicular), e entre o $19^{\circ}$ e $\circ 24^{\circ}$ dia (fase lútea), foram coletadas amostras de sangue para dosagem de estradiol, progesterona, testosterona, FSH, LH, prolactina, T3, T4 livre e TSH. Semanalmente, até o início do próximo ciclo, foram realizadas USG pélvicas. Os momentos nos quais esses exames foram realizados estão ilustrados na Figura 1. 


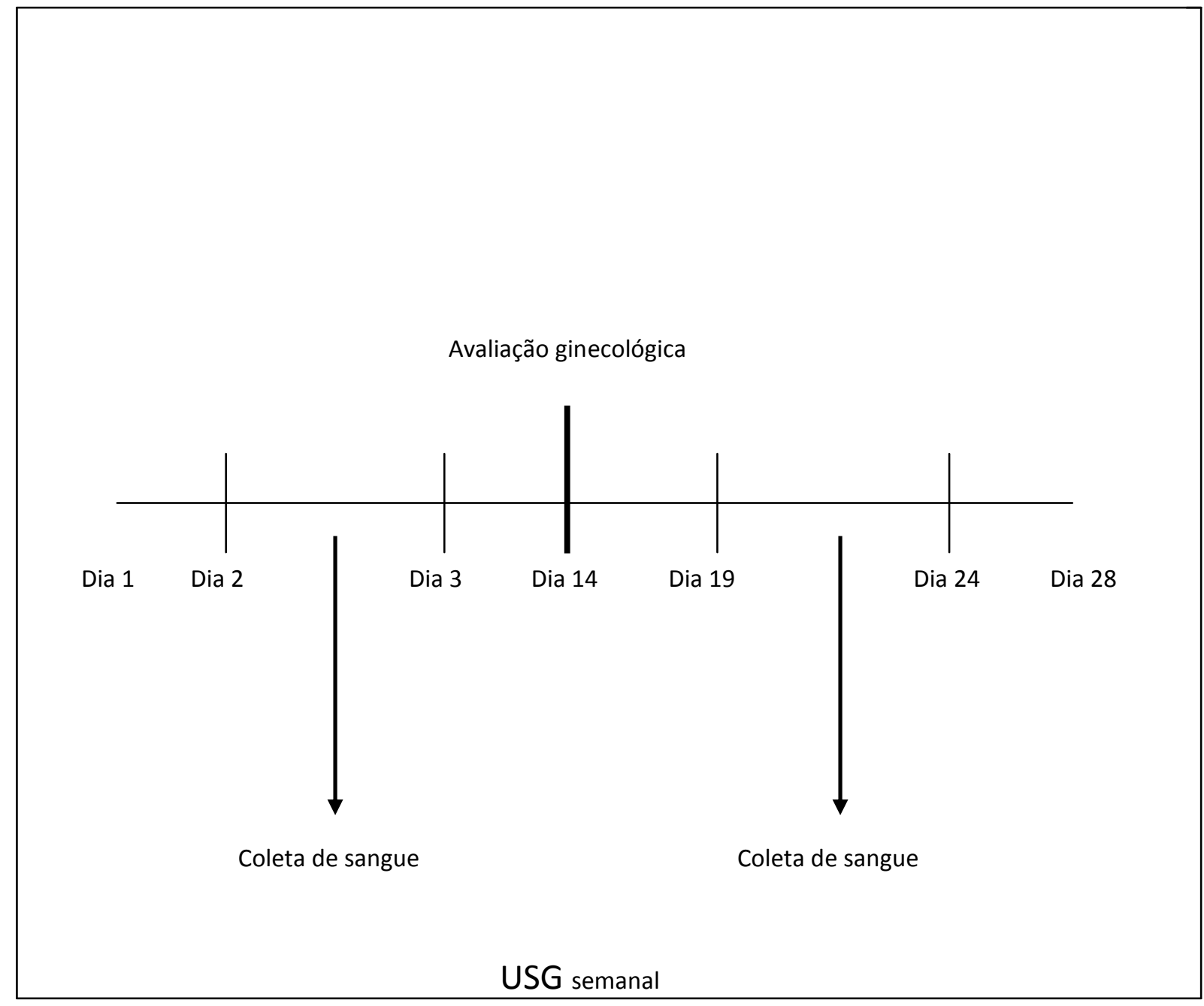

Figura 1: Representação esquemática dos exames a serem realizados em um ciclo de 28 dias 


\subsubsection{Gestação}

A ocorrência de gestação é o único parâmetro direto de função gonadal normal deste estudo. Portanto, quando presente, a gestação foi considerada critério absoluto.

A presença de gestação prévia recente (menos de seis meses) ou no momento da admissão no protocolo foi considerada como demonstrativo de função gonadal normal. Neste caso, a paciente não foi submetida aos demais exames para a determinação da sua função gonadal, pressupondo-se que naquele momento ela era adequada.

\subsubsection{Ciclo menstrual e dismenorréia}

Os dados referentes ao ciclo menstrual foram obtidos através de questionário como previamente descrito no item 2.2 e do calendário.

O critério de ciclo menstrual "normal" adotado neste estudo foi de intervalo regular entre 25 e 35 dias e duração de 3 a 7 dias. A dismenorréia foi definida como menstruação dolorosa, com cólicas uterinas de intensidade variável, habitualmente nos primeiros dois dias do ciclo menstrual (Spritzer et al.,2001).

\subsubsection{Hormônios}

A avaliação hormonal foi realizada no Laboratório do Instituto Central do HCFMUSP com dosagens séricas de FSH, LH, estradiol, progesterona, prolactina, testosterona, T3, T4, T4 livre e TSH. Os níveis séricos dos hormônios foram medidos através da técnica de imunofluorimetria, tendo sido utilizados os "kits" "DELFIA" (Wallac Oy, Turku,Finland). Os hormônios foram aferidos na fase proliferativa (entre o $2^{\circ}$. e $3^{\circ}$. dia do ciclo menstrual, em média entre o $1^{\circ}$. e $4^{\circ}$. dia) e fase secretora (entre 
o $19^{\circ}$. e $24^{\circ}$. dia do ciclo menstrual, em média no $20^{\circ}$. dia). Os valores normais dos hormônios nas fases folicular e lútea estão demonstrados na Tabela 1.

A coleta de exames de função tireoidiana foi realizada, pois disfunções dos hormônios tireoidianos podem levar a disfunção gonadal de causa endocrinológica (Giordano, 2001).

Tabela 1: Valores normais dos hormônios nas fases folicular e lútea

\begin{tabular}{|c|c|c|c|}
\hline & $\begin{array}{l}\text { Níveis durante } \\
\text { todo o ciclo }\end{array}$ & Fase folicular & Fase lútea \\
\hline FSH & --- & 2,4 a $9,3 \mathrm{IU} / \mathrm{L}$ & até $8,0 \mathrm{IU} / \mathrm{L}$ \\
\hline LH & -- & 2,2 a $6,8 \mathrm{IU} / \mathrm{L}$ & até $12,8 \mathrm{IU} / \mathrm{L}$ \\
\hline Estradiol & --- & 22 a $215 \mathrm{pg} / \mathrm{ml}$ & 22 a $232 \mathrm{pg} / \mathrm{ml}$ \\
\hline Progesterona & --- & 0,4 a $1,1 \mathrm{ng} / \mathrm{ml}$ & 3,6 a $21,7 \mathrm{ng} / \mathrm{ml}$ \\
\hline Prolactina & 2,0 a $15,0 \mathrm{ng} / \mathrm{ml}$ & --- & -- \\
\hline Testosterona & até $98 \mathrm{ng} / \mathrm{dl}$ & -- & -- \\
\hline T3 & 12 a 20 anos : 72 a $214 \mathrm{ng} / \mathrm{dl}$ & --- & --- \\
\hline T4 & $>12$ anos $: 4,5$ a $12,0 \mu \mathrm{g} / \mathrm{dl}$ & --- & --- \\
\hline T4 livre & 0,7 a $1,5 \mathrm{ng} / \mathrm{dl}$ & --- & --- \\
\hline TSH & $\begin{array}{l}11 \text { a } 15 \text { anos : } 0,50 \text { a } 4,90 \mu \mathrm{U} / \mathrm{ml} \\
16 \text { a } 20 \text { anos : } 0,50 \text { a } 4,40 \mu \mathrm{U} / \mathrm{ml}\end{array}$ & -- & --- \\
\hline
\end{tabular}

dl: decilitro;IU: unidades internacionais; L:litro; $\mu \mathrm{g}$ : microgramas; $\boldsymbol{\mu U}$ : microunidades;ml: mililitro; $\mathbf{n g}$ :nanogramas; pg: picogramas.

\subsubsection{Ultra-sonografias pélvicas abdominais seriadas}

As ultra-sonografias pélvicas abdominais (USG) seriadas foram realizadas no Serviço de Radiologia Pediátrica do ICr-HC-FMUSP sob a supervisão da Dra.Sílvia Maria Sucena da Rocha (Membro Titular da Sociedade Brasileira de Radiologia). 
Dois a cinco USG foram realizadas em cada paciente. A mesma ultrasonografista avaliou todos os exames. O parâmetro ultra-sonográfico considerado como característico de ovulação foi a evidência de desenvolvimento do folículo dominante (diâmetro médio máximo de 20 a $24 \mathrm{~mm}$ ) com seu posterior desaparecimento. Outros parâmetros foram avaliados: formação do corpo lúteo, diâmetro médio do endométrio (6 a $10 \mathrm{~mm})$ e volumes ovarianos $\left(8 \mathrm{a} 10 \mathrm{~cm}^{3}\right)$ (Ferreira et al.,2001;Giacobbe et al.,1997).

Concluindo, os parâmetros clínicos e/ou laboratoriais definidos, neste estudo, como indicadores de função gonadal normal para o sexo feminino foram:

1. presença de gravidez atual ou prévia (nos últimos seis meses)

2. ciclo menstrual normal

3. presença de dismenorréia

4. níveis hormonais adequados nas duas fases do ciclo em que estes foram medidos

5. USG pélvicas compatíveis com padrão ovulatório

Para este estudo, foram considerados indicadores de função gonadal normal a presença de gestação como critério direto. Todos os demais foram considerados critérios indiretos; sendo que dos critérios indiretos, foram considerados a presença de dois critérios clínicos como sugestivos de função gonadal normal, ou um critério laboratorial indicativo de normalidade. 


\section{Metodologia para a análise estatística}

Para este estudo, duas análises distintas foram realizadas:

\subsection{Comparação entre pacientes e controles}

\section{Variáveis avaliadas:}

(1) dados demográficos: idade, escolaridade, classe sócio-econômica;

(2) comportamento sexual: idade da primeira relação sexual, atividade sexual (freqüência no último mês), número de parceiros (no último ano), masturbação, libido, orgasmo, uso de contracepção;

(3) dados sobre a função gonadal: idade da menarca, duração e intervalo do ciclo menstrual, gestação atual ou prévia.

Metodologia Estatística: Os dados contínuos foram descritos através dos valores mínimo e máximo, mediana, média e desvio padrão e os dados categorizados, através de freqüências absolutas e relativas.

As comparações dos grupos epilepsia e controle quanto às variáveis contínuas foram feitas adotando-se o teste t de Student para amostras independentes ou o teste de Mann-Whitney, caso a suposição de distribuição Normal fosse violada. Tal suposição foi verificada por meio do gráfico de probabilidade normal e dos testes Shapiro-Wilks e Kolmogorov-Smirnov.

As comparações dos grupos quanto às variáveis categorizadas foram feitas pelos testes qui-quadrado de Pearson ou exato de Fisher. 


\subsection{Comparação com as variáveis clínicas da epilepsia no grupo de}

pacientes

Variáveis avaliadas:

(1)

dados sobre o comportamento sexual: idade da primeira relação sexual, atividade sexual, libido, orgasmo

(2) dados sobre a função gonadal: idade da menarca, duração e intervalo do ciclo menstrual, presença de dismenorréia, presença de gestação, ocorrência de abortamento.

Variáveis clínicas da epilepsia:duração, freqüência de crises, tipo de crises e de síndrome, presença de crises TCG, terapêutica atual e prévia (se monoterapia ou politerapia, uso atual ou pregresso de VPA), controle de crises no momento da avaliação.

Metodologia Estatística: Para esta análise foi utilizada a análise de variância (ANOVA), com o programa SPSS para Windows versão 11,0. 
Resultados 


\section{Caracterização do grupo estudado}

Foram selecionadas 57 pacientes do ambulatório de epilepsia do Instituto de Psiquiatria do Hospital das Clínicas da Faculdade de Medicina da Universidade de São Paulo (Tabela 2). Após entrevista e o consentimento dos pais ou responsáveis, ou da própria paciente para maiores de 18 anos, trinta e cinco pacientes foram incluídas na pesquisa.

Tabela 2: Entrevistas realizadas e amostra final de pacientes

\begin{tabular}{l|c}
\hline & Protocolo \\
\hline Pacientes Avaliadas & $\mathbf{5 7}$ \\
\hline Não preenchiam critérios & 14 \\
\hline Recusas & 8 \\
\hline Amostra Final & 35 \\
\hline
\end{tabular}

A média de idade das 35 pacientes avaliadas foi de 16,1 anos (variando entre 12 a 20 anos; $\left.\mathrm{DP}_{ \pm} 2,28\right)$, com escolaridade de 8,8 anos $\left(\mathrm{DP}_{ \pm} 1,99\right)$. Quanto à classificação sócio-econômica, 45,7\% pertenciam às classes B e C e 54,3\% às classes D e E, segundo o critério ABA (Associação Brasileira de Anunciantes) e Abipeme (Associação Brasileira dos Institutos de Pesquisa de Mercado) (Almeida e Wickerhauser,1991).

O início da epilepsia ocorreu durante a adolescência em 25 (71,4\%) destas pacientes (média de 3,1 anos de duração da doença, $\mathrm{DP}_{ \pm} 2,15$ ). Em dez pacientes $(28,6 \%)$, as crises epilépticas se iniciaram durante a infância (média de duração de 11 anos, $\left.\mathrm{DP}_{ \pm} 4,96\right)$. Quanto à síndrome epiléptica, cinco $(14,3 \%)$ tinham epilepsia parcial 
sintomática, 23 (65,7\%) epilepsia parcial criptogênica e sete (20\%) apresentavam epilepsia generalizada idiopática. Vinte e seis pacientes $(74,2 \%)$ encontravam-se em monoterapia exclusiva, duas $(5,7 \%)$ com um benzodiazepínico associado à primeira droga, seis pacientes $(17,1 \%)$ sob politerapia com duas DAE e uma $(3,0 \%)$ em politerapia com três DAE.

As características da epilepsia, da síndrome epiléptica e do tratamento destas pacientes estão descritas nas Tabelas 3, 4 e 5. 
Tabela 3: Características da epilepsia e da síndrome epiléptica em 35 pacientes

\begin{tabular}{|c|c|c|c|c|c|c|}
\hline Paciente & $\begin{array}{c}\text { Idade } \\
\text { (anos) }\end{array}$ & $\begin{array}{c}\text { Duração da } \\
\text { Epilepsia } \\
\text { (anos) }\end{array}$ & Freqüência de crises & Classificação & Síndrome & Etiologia \\
\hline 1 & 16 & 16 & controlada há $2 a$ & CPC & parcial sintomática & ulegiria frontal $\mathrm{E}$ \\
\hline 2 & 18 & 9 & mensal & TCG 1aria. & generalizada idiopática & \\
\hline 3 & 13 & 1 & quinzenal & CPS-TCG 2aria & parcial criptogênica & \\
\hline 4 & 17 & 1 & controlada há 1a & TCG & parcial criptogênica & \\
\hline 5 & 14 & 2 & controlada há 2a & TCG 1aria. & generalizada idiopática & \\
\hline 6 & 14 & 3 & anual & TCG 1aria. & generalizada idiopática & \\
\hline 7 & 17 & 1 & anual & CPS-TCG & parcial criptogênica & \\
\hline 8 & 15 & 6 & quinzenal & CPC & parcial criptogênica & \\
\hline 9 & 18 & 16 & anual & CPC-TCG 2aria. & parcial sintomática & displasia transmantle frontal $\mathrm{E}$ \\
\hline 10 & 16 & 2 & anual & CPC-TCG 2aria. & parcial criptogênica & \\
\hline 11 & 12 & 7 & controlada há $3 a$ & CPC-TCG 2aria. & parcial criptogênica & \\
\hline 12 & 16 & 3 & anual & mio-TCG 1aria. & generalizada idiopática & \\
\hline 13 & 15 & 1 & anual & TCG 2aria. & parcial sintomática & heterotopia periventricular \\
\hline 14 & 19 & 9 & mensal & CPS-CPC-TCG 2aria. & parcial criptogênica & \\
\hline 15 & 16 & 1 & mensal & mio-TCG 1aria. & generalizada idiopática & \\
\hline 16 & 14 & 7 & semanal & CPS-CPC & parcial criptogênica & \\
\hline 17 & 18 & 3 & anual & CPC-TCG 2aria. & parcial criptogênica & \\
\hline 18 & 12 & 5 & semanal & CPS-CPC & parcial sintomática & EMT bilateral \\
\hline 19 & 13 & 3 & mensal & CPS-CPC & parcial criptogênica & \\
\hline 20 & 19 & 8 & semestral & CPS-TCG 2aria. & parcial criptogênica & \\
\hline 21 & 15 & 2 & anual & CPS-CPC-TCG 2aria. & parcial criptogênica & \\
\hline 22 & 13 & 3 & anual & CPS-CPC & parcial criptogênica & \\
\hline 23 & 20 & 18 & controlada há 8a & CPC & parcial sintomática & displasia frontal $\mathrm{E}$ \\
\hline 24 & 19 & 3 & anual & CPC-TCG 2aria. & parcial criptogênica & \\
\hline 25 & 14 & 3 & semestral & mio-TCG 1aria. & generalizada idiopática & \\
\hline 26 & 14 & 0,5 & mensal & CPS-TCG 2aria. & parcial criptogênica & \\
\hline 27 & 19 & 6 & controlada há $3 a$ & CPS-CPC & parcial criptogênica & \\
\hline 28 & 16 & 4 & anual & ausência-TCG 1aria. & generalizada idiopática & \\
\hline 29 & 19 & 10 & diária & CPS-CPC-TCG 2aria. & parcial criptogênica & \\
\hline 30 & 16 & 4 & controlada há 2a & CPS-CPC & parcial criptogênica & \\
\hline 31 & 17 & 2 & semestral & CPS-CPC-TCG 2aria. & parcial criptogênica & \\
\hline 32 & 19 & 5 & mensal & CPS-CPC & parcial criptogênica & \\
\hline 33 & 19 & 5 & mensal & CPS-CPC-TCG 2aria. & parcial criptogênica & \\
\hline 34 & 17 & 16 & anual & CPC-TCG 2aria. & parcial criptogênica & \\
\hline 35 & 15 & 2 & semestral & CPC-TCG 2aria. & parcial criptogênica & \\
\hline
\end{tabular}

a: anos; CPS: crise parcial simples; CPC: crise parcial complexa; TCG 1aria: crise tônico-clônica primariamente generalizada; TCG 2ária: crise tônico-clônica secundariamente generalizada; mio: crises mioclônicas; EMT: esclerose mesial temporal; E: esquerda. 
Tabela 4: Tratamento medicamentoso da epilepsia em 35 pacientes

\begin{tabular}{|c|c|c|c|}
\hline Paciente & $\begin{array}{l}\text { Idade } \\
\text { (anos) }\end{array}$ & Terapêutica pregressa & Terapêutica atual \\
\hline 1 & 16 & & CBZ $400 \mathrm{mg}$ \\
\hline 2 & 18 & VPA $500 / C B Z 400 / P B ~ 100 \mathrm{mg}$ & $\mathrm{PB} 100 / \mathrm{CBZ} 400 \mathrm{mg}$ \\
\hline 3 & 13 & CBZ 600/PB $100 \mathrm{mg}$ & VPA $1,5 \mathrm{~g} / T P M 25 \mathrm{mg}$ \\
\hline 4 & 17 & & VPA $250 \mathrm{mg}$ \\
\hline 5 & 14 & & VPA $1 \mathrm{~g}$ \\
\hline 6 & 14 & & VPA $500 \mathrm{mg}$ \\
\hline 7 & 17 & & $\mathrm{CBZ} 600 \mathrm{mg}$ \\
\hline 8 & 15 & & CLB $20 \mathrm{mg}$ \\
\hline 9 & 18 & & $\mathrm{CBZ} 900 \mathrm{mg}$ \\
\hline 10 & 16 & VPA $750 \mathrm{mg}$ & CBZ $400 \mathrm{mg}$ \\
\hline 11 & 12 & PB $100 \mathrm{mg}$ & VPA $500 \mathrm{mg}$ \\
\hline 12 & 16 & & VPA $1,0 \mathrm{~g}$ \\
\hline 13 & 15 & & CBZ $400 \mathrm{mg}$ \\
\hline 14 & 19 & PHT 350/PB $100 \mathrm{mg}$ & $\mathrm{CBZ} 400 / \mathrm{PB} 100 / \mathrm{PHT} 200 \mathrm{mg}$ \\
\hline 15 & 16 & $\mathrm{CBZ} 400 / \mathrm{PB} 100 \mathrm{mg}$ & VPA $1,5 \mathrm{~g} / \mathrm{TPM} 50 \mathrm{mg}$ \\
\hline 16 & 14 & VPA $1 \mathrm{~g} / \mathrm{CBZ} 400 \mathrm{mg}$ & OXC 1050/TPM $150 \mathrm{mg}$ \\
\hline 17 & 18 & & PB $100 \mathrm{mg}$ \\
\hline 18 & 12 & PB $100 / \mathrm{OXC} 600 / \mathrm{VPA} 500 \mathrm{mg}$ & LMT $100 \mathrm{mg}$ \\
\hline 19 & 13 & CBZ 200/PB 100/PHT $400 \mathrm{mg}$ & PHT 300/VPA $750 \mathrm{mg}$ \\
\hline 20 & 19 & VPA $250 \mathrm{mg}$ & CBZ $1000 / C L B 10 \mathrm{mg}$ \\
\hline 21 & 15 & & CBZ $300 \mathrm{mg}$ \\
\hline 22 & 13 & & CBZ $300 \mathrm{mg}$ \\
\hline 23 & 20 & $\mathrm{~PB} 100 / \mathrm{VPA} 1 \mathrm{~g} / \mathrm{CLN} 2 \mathrm{mg}$ & $\mathrm{CBZ} 600 / \mathrm{CLB} 20 \mathrm{mg}$ \\
\hline 24 & 19 & CBZ $300 \mathrm{mg}$ & OXC $450 \mathrm{mg}$ \\
\hline 25 & 14 & & VPA $1,5 \mathrm{~g}$ \\
\hline 26 & 14 & & PB $100 \mathrm{mg}$ \\
\hline 27 & 19 & PB $100 \mathrm{mg}$ & VPA 2g \\
\hline 28 & 16 & VPA $500 \mathrm{mg}$ & VPA $250 \mathrm{mg}$ \\
\hline 29 & 19 & & PHT 200/PB $100 \mathrm{mg}$ \\
\hline 30 & 16 & & $\mathrm{CBZ} 400 \mathrm{mg}$ \\
\hline 31 & 17 & & $\mathrm{CBZ} 200 \mathrm{mg}$ \\
\hline 32 & 19 & PB $100 \mathrm{mg}$ & PB $150 \mathrm{mg}$ \\
\hline 33 & 19 & & PHT $100 \mathrm{mg}$ \\
\hline 34 & 17 & & CBZ $400 \mathrm{mg}$ \\
\hline 35 & 15 & & PB $100 \mathrm{mg}$ \\
\hline
\end{tabular}

CBZ: carbamazepina; CLB: clobazam; CLN: clonazepam; OXC: oxcarbazepina; PB: fenobarbital; PHT: fenitoína; VPA: ácido valpróico; mg: miligramas; g: gramas. 
Tabela 5: Características do tratamento medicamentoso em 35 pacientes

\begin{tabular}{c|c}
\hline & $\mathrm{N}=35$ \\
\hline Monoterapia exclusiva, sem VPA & $18(51,4 \%)$ \\
\hline Monoterapia em associação com BDZ & $2(5,7 \%)$ \\
\hline Monoterapia exclusiva, com VPA & $8(22,8 \%)$ \\
\hline Politerapia sem VPA & $4(11,4 \%)$ \\
\hline Politerapia com VPA & $3(8,7 \%)$ \\
\hline
\end{tabular}

BDZ: benzodiazepínico;VPA:valproato

\section{Caracterização da função e do comportamento sexual}

\subsection{Análise Descritiva}

Das 35 pacientes avaliadas, 18 adolescentes (51,4\%) relataram a primeira relação sexual, e 15 (42,8\%) delas eram sexualmente ativas no momento da entrevista. A idade da primeira relação sexual variou entre 11 a 17 anos (média de 14,6 anos, $\left.\mathrm{DP}_{ \pm} 1,37\right)$.

Quanto à função sexual, das 18 pacientes que tiveram a primeira relação sexual, cinco não responderam ao questionamento sobre libido e orgasmo. Onze das 13 pacientes que responderam ao questionário (84,6\%) afirmaram ter libido presente, e todas referiram orgasmo em pelo menos algumas relações sexuais. Das pacientes com diminuição da libido, uma encontrava-se controlada das crises epilépticas e em 
monoterapia, e a outra estava controlada das crises, em politerapia transitória para mudança de DAE,em virtude do aparecimento da SOP, com relação temporal com o início do tratamento com VPA.

Das pacientes sexualmente ativas $(n=15)$ no momento da entrevista, oito $(53,3 \%)$ tiveram um parceiro no último ano, uma paciente $(6,6 \%)$ referiu dois parceiros, uma $(6,6 \%)$ referiu quatro parceiros, e cinco pacientes não responderam ao questionamento. Sete em quinze pacientes (46,6\%) mantinham uma freqüência de relações sexuais de pelo menos uma vez por semana, uma (6,6\%) quinzenalmente, e duas $(13,3 \%)$ esporadicamente.

Somente duas pacientes $(5,7 \%)$ referiram masturbar-se, enquanto duas $(5,7 \%)$ recusaram-se a responder à questão. As demais $(88,6 \%)$ responderam que não se masturbavam.

\subsection{Comparação com o grupo controle}

Não foi observada diferença estatisticamente significante entre as adolescentes com epilepsia e o grupo controle quanto à escolaridade $(p=0,15)$, idade da primeira relação sexual $(p=0,54)$, atividade sexual no momento da entrevista $(p=0,23)$, freqüência de relações sexuais no último mês $(p=0,86)$, número de parceiros no último ano $(p=0,20)$, libido $(p=1,00)$, orgasmo $(p=0,23)$, uso de contraceptivos $(p=0,24)$ e masturbação $(p=0,51)$.

Foi observada uma proporção maior de adolescentes pertencentes às classes D e $E$ no grupo de pacientes com epilepsia, em relação às controles, porém sem significância estatística $(p=0.06)$. 


\subsection{Comparação entre as variáveis da função e comportamento sexual e}

as variáveis clínicas da epilepsia

Não houve diferença estatisticamente significante entre idade da primeira relação sexual, atividade sexual no momento da entrevista, freqüência de relações sexuais no último mês, número de parceiros no último ano, libido, uso de contraceptivos e variáveis clínicas da epilepsia (Anexo III).

Orgasmo não foi avaliado, pois 100\% das pacientes referiram apresentá-lo.

\section{Educação sexual}

Orientação sexual para contracepção: A escola foi responsável pela orientação sexual e de contracepção em $40 \%$ dos casos (14/35); o ginecologista em 14,3\% (5/35);o neurologista em 2,9\% das pacientes (1/35), e em 2,9\% por outro profissional de saúde (1/35). Nove pacientes (25,7\%) não receberam qualquer tipo de orientação. Cinco pacientes não responderam ao questionamento.

O uso de método contraceptivo foi usado sob orientação médica por sete das 18 pacientes que já tiveram a primeira relação sexual (38,8\%), e outras $11(61,2 \%)$ por iniciativa própria. O preservativo masculino foi o método escolhido por 15 pacientes (83,3\%), o anticoncepcional oral em um caso (5,5\%), o dispositivo intra-uterino em outro caso (5,5\%), e uma paciente utilizava anticoncepcional injetável mensal (5,5\%).

Nove de 18 pacientes $(50,0 \%)$ referiram utilizar o preservativo masculino também como método de prevenção de DST, porém 11,1\% (2/18) admitiram não utilizá-lo em todas as relações sexuais. Apenas 27,7\% (5/18) das pacientes referiram ter recebido orientação em consultas médicas de rotina quanto à prevenção de DST, 
incluindo o vírus da imunodeficiência humana (HIV) e hepatites B e C. Três das 18 (16,6\%) pacientes conviviam com o parceiro numa relação estável.

Quanto ao conhecimento a respeito de contracepção de emergência ( $n=35)$, $50,0 \%$ das pacientes (15/35) conheciam o termo, mas apenas $20,0 \%(6 / 35)$ declarou saber como utilizá-la. Já uma paciente referiu ter utilizado uma vez tal contraceptivo.

Do grupo estudado $(n=35)$, apenas $54,2 \%$ das pacientes (19/35) usavam ácido fólico regularmente, e $68,4 \%$ das pacientes (13/19) sabiam o motivo pelo qual o usavam. Em um caso a prescrição foi realizada pelo ginecologista, sendo que as demais foram feitas pelo médico de seguimento da epilepsia (neurologista ou neuropediatra).

Gestação: Treze $(72,2 \%)$ das 18 pacientes que já relataram a primeira relação sexual já haviam engravidado, e destas, quatro $(33,3 \%)$ pacientes tinham engravidado mais de uma vez (três duas vezes e uma três vezes). Destas quatro pacientes, uma não planejou nenhuma das duas gestações, uma, planejou a primeira, mas não a segunda, uma planejou a última, mas não as duas anteriores e uma afirma ter planejado as duas, perfazendo um total de 12 de 13 pacientes que ao menos uma vez teve uma gestação não desejada.

Todas as gestações não planejadas ocorreram em virtude de utilização incorreta do preservativo masculino, exceto uma, que ocorreu por uso incorreto de anticoncepcional injetável.

Todas as pacientes consideraram como planejamento o desejo de engravidar, sem conhecimento sobre a doença ou contato com profissional da área de saúde previamente à gestação em andamento.

Os dados relacionados à gravidez destas pacientes estão demonstrados nas

\section{Tabelas 6 e 7.}


Tabela 6: Controle de crises durante a gestação

\begin{tabular}{|c|c|c|c|c|}
\hline & $\begin{array}{r}\text { Idade } \\
\text { (anos) }\end{array}$ & Gestações & Padrão de crises (última gravidez) & Tipo de crises \\
\hline & & & & \\
\hline 1 & 18 & $\overline{I G}$ & Inalterado & sem crises \\
\hline 2 & 16 & $\bar{I} \mathrm{G}$ & Inalterado & sem crises \\
\hline 3 & 19 & $\overline{I I G}$ & Inalterado & crises parciais semanais \\
\hline 4 & 19 & $\overline{I G}$ & Inalterado & sem crises \\
\hline 5 & 19 & $\bar{I} \mathrm{G}$ & Inalterado & sem crises \\
\hline 6 & 16 & $\bar{I} \mathrm{G}$ & Piora & crise de ausência no puerpério \\
\hline 7 & 19 & IilïG & Melhora & crises parciais e TCG semanais \\
\hline 8 & 17 & $\overline{I I G}$ & Piora & duas crises TCG \\
\hline 9 & 19 & IG & Piora & uma crise parcial \\
\hline 10 & 19 & IIIG & Piora & crise TCGG por suspensão medicaçẫo \\
\hline 111 & 17 & $\overline{I G}$ & Inalterado & sem crises \\
\hline 12 & 15 & $\overline{I G}$ & Inalterado & sem crises \\
\hline 13 & 17 & $\bar{I} \mathrm{G}$ & Piora & crises parciais por reduçẫo da medicaçẫo \\
\hline
\end{tabular}

a: anos; G:gestação;crise TCG: crise tônico-clônica generalizada

Tabela 7: Planejamento da gravidez e dados do recém-nascido

\begin{tabular}{|c|c|c|c|c|c|}
\hline & $\begin{array}{l}\text { Idade } \\
\text { (anos) }\end{array}$ & Tratamento & Gesta I & Gesta II & Gesta III \\
\hline & & & & & \\
\hline 1 & 18 & CBZ $900 \mathrm{mg}$ & NP/aborto & & \\
\hline 2 & 16 & CBZ $400 \mathrm{mg}$ & NP/aborto & & \\
\hline 3 & 19 & CBZ 400/PB 100/PHT $200 \mathrm{mg}$ & P/saudável & NP/saudável & \\
\hline 4 & 19 & CBZ 1000/CLB $10 \mathrm{mg}$ & NP/aborto & & \\
\hline 5 & 19 & VPA $2 \mathrm{~g}$ & NP/saudável & & \\
\hline 6 & 16 & VPA $250 \mathrm{mg}$ & NP/saudável & & \\
\hline 7 & 19 & PHT 200/PB $100 \mathrm{mg}$ & NP/saudável & NP/aborto & P/saudável \\
\hline 8 & 17 & CBZ $200 \mathrm{mg}$ & P/anomalia cromossômica & P/abandonou seguimento & \\
\hline 9 & 19 & PB $150 \mathrm{mg}$ & NP/abandonou seguimento & & \\
\hline 10 & 19 & PHT $100 \mathrm{mg}$ & NP/saudável & NP/abandonou seguimento & \\
\hline 11 & 17 & CBZ $400 \mathrm{mg}$ & NP/abandonou seguimento & & \\
\hline 12 & 15 & PB $100 \mathrm{mg}$ & NP/abandonou seguimento & & \\
\hline 13 & 17 & VPA 1,0g/LMT $100 \mathrm{mg}$ & NP/aborto & & \\
\hline
\end{tabular}

CBZ: carbamazepina; CLB: clobazam; Gesta: gestação; LMT: lamotrigina; NP: não planejada; P: planejada;PB: fenobarbital; PHT: fenitoína; VPA: ácido valpróico; mg:miligramas; g:gramas. 
Cinco pacientes $(38,4 \%)$ apresentaram abortamento. Uma paciente relatou abortamento induzido e uma se negou a relatar as condições nas quais o aborto ocorreu. Um dos recém-nascidos tinha uma anomalia cromossômica e viveu apenas três dias. Cinco pacientes $(38,4 \%)$ deram à luz crianças saudáveis. Cinco gestantes com epilepsia (38,4\%) abandonaram o seguimento clínico durante o acompanhamento neurológico.

\section{Função gonadal}

\section{Análise Descritiva}

Das 35 pacientes entrevistadas, treze tinham engravidado nos seis meses prévios à admissão no estudo ou durante a realização do mesmo; uma paciente encontrava-se em tratamento da síndrome dos ovários policísticos (SOP); oito pacientes não quiseram realizar os exames laboratoriais (perfil hormonal) e radiológicos (ultra-sonografia pélvica seriada); quatro iniciaram uso de medicações contendo hormônios ou anticoncepcionais orais; cinco pacientes concluíram apenas a fase de realização do calendário dos ciclos menstruais; cinco pacientes iniciaram os exames séricos e de imagem, saindo do estudo antes da conclusão, e duas pacientes concluíram todos os exames.

Ciclo Menstrual e Dismenorréia: A média de idade da menarca das 35 pacientes incluídas no estudo foi de 11,8 anos, com $D P \pm 1,59$. Quatorze de 35 pacientes $(40,0 \%)$ tinham ciclos menstruais irregulares. Vinte e quatro de 35 pacientes $(68,6 \%)$ referiram apresentar dismenorréia. Nenhuma paciente tinha história atual ou pregressa de amenorréia.

Uma paciente encontrava-se em tratamento para a síndrome dos ovários

policísticos, definida clinicamente nesta paciente pela presença irregularidade 
menstrual, com intervalo médio dos ciclos menstruais superior a 35 dias, sinais de hiperandrogenismo (pêlos em excesso e com distribuição masculina, acne), obesidade e presença de ovários policísticos à USG pélvica, caracterizando função gonadal anormal. Tais sinais e sintomas ocorreram após a introdução de VPA para o controle das crises.

Perfil Hormonal e USG pélvica: Das seis pacientes que realizaram o perfil hormonal, todas apresentaram níveis basais de FSH dentro dos limites da normalidade. Das cinco pacientes que realizaram USG pélvicas seriadas, foi observada a formação de corpo lúteo em uma paciente, e de cisto folicular em outra paciente. Não foram observadas anormalidades estruturais em nenhum caso. Os resultados das dosagens hormonais nas duas fases do ciclo menstrual e da USG pélvica estão demonstrados nos Anexos IV e V.

\section{Gestação:}

Treze $(37,1 \%)$ das 35 pacientes com epilepsia já tinham engravidado, sendo que quatro já tinham engravidado mais de uma vez. Destas treze pacientes, três tinham engravidado nos seis meses prévios à admissão no estudo, quatro pacientes estavam grávidas à admissão, e seis pacientes engravidaram durante o estudo.

\section{Função Gonadal Adequada}

Em sete de 35 adolescentes (20,0\%), não foram obtidos parâmetros suficientes para a determinação da função gonadal, sendo excluídas desta análise. Das 28 pacientes restantes, dezenove $(67,8 \%)$ foram consideradas como tendo função gonadal normal, sendo 13 gestantes e seis com dados clínicos e laboratoriais.

Uma paciente $(3,5 \%)$ teve função gonadal anormal devido à presença de SOP, uma causa potencialmente reversível de disfunção gonadal, relacionada à medicação (VPA). 
Em cinco pacientes sem dados laboratoriais $(17,8 \%)$, os dados clínicos (presença de dismenorréia e ciclos menstruais regulares) foram sugestivos de função gonadal normal.

Em três pacientes $(10,9 \%)$, os dados clínicos sugeriram função gonadal anormal.

Portanto, das 28 pacientes com avaliação conclusiva para a determinação da função gonadal, vinte e quatro $(85,6 \%)$ apresentaram dados clínicos que sugerem normalidade. Os resultados estão demonstrados na Tabela 8 e Anexo VI.

Dentre as pacientes com função gonadal normal, o tempo médio desde a menarca até o momento da avaliação foi de cinco anos, com $\mathrm{DP}_{ \pm} 2,62$.

Nas pacientes com dados clínicos e/ou laboratoriais de função gonadal anormal, o tempo médio desde a menarca até a avaliação foi de 1,8 anos, com $\mathrm{DP}_{ \pm 2}, 09$.

Tabela 8: Função gonadal nas pacientes com epilepsia e avaliação conclusiva dos parâmetros metodológicos

\begin{tabular}{l|l|l}
\hline Função Gonadal Anormal & 1 & $3,5 \%$ \\
Clínico e Laboratorial & & \\
\hline $\begin{array}{l}\text { Função Gonadal Normal } \\
\text { Gestantes }\end{array}$ & 19 & $67,8 \%$ \\
$\begin{array}{l}\text { Dados Clínicos e Laboratoriais } \\
\text { Função Gonadal Clinicamente }\end{array}$ & 6 & $31,6 \%$ \\
\hline $\begin{array}{l}\text { Normal } \\
\text { Anormão Gonadal Clinicamente }\end{array}$ & 5 & $17,8 \%$ \\
\hline $\mathbf{N}$ & 3 & $10,9 \%$ \\
\hline
\end{tabular}




\subsection{Comparação com controles sem doença crônica}

Não houve diferença em relação à menarca $(p=0,82)$.

Houve diferença quanto à regularidade dos ciclos menstruais, com maiores índices de irregularidade menstrual $(p=0,05)$, duração dos ciclos menstruais, com fluxo menstrual superior a 7 dias $(p=0,0003)$ e intervalo dos ciclos mais longos $(p=0,0244)$ entre as adolescentes com epilepsia.

Foi observada diferença estatisticamente significante quanto à presença de gravidez, com maiores índices entre as adolescentes com epilepsia $(p<0,0001)$.

\subsection{Comparação com variáveis clínicas da epilepsia}

Houve relação entre menarca mais precoce com freqüência de crises mais elevadas $(p=0,009)$ e com o uso da valproato pregresso, no período da menarca $(p=0,04)$.

Houve uma tendência a ciclos irregulares relacionados com maior duração da epilepsia $(p=0,067)$, a despeito do seu controle no momento da avaliação. Presença de crises TCG teve relação com ciclos mais prolongados $(p=0,03)$, independente da síndrome epiléptica.

Houve relação entre a presença de dismenorréia e o uso de valproato $(p=0,04)$.

A duração do fluxo não teve relação com as variáveis da epilepsia.

Os resultados estão demonstrados no Anexo VII. 
Discussão 
Atualmente, terapêuticas mais agressivas têm sido utilizadas no tratamento de pacientes com doenças crônicas. O prognóstico mais favorável tem permitido que mais pacientes atinjam a idade adulta, iniciem sua vida sexual e, conseqüentemente, tenham preocupações a respeito de sua função sexual e gonadal em longo prazo (Silva et al.,2002).

Novos tratamentos aumentam a expectativa de vida, mas podem ter efeitos deletérios a vários órgãos e sistemas. A despeito do número crescente de adolescentes e adultos jovens com doenças crônicas, há poucos estudos na literatura médica que avaliem a função sexual e a função gonadal desses pacientes, sobretudo quando se trata de epilepsia. Mulheres com epilepsia apresentam maiores índices de disfunção gonadal, com maior número de ciclos anovulatórios e disfunções sexuais, com diminuição da libido (Isojarvi, 2007; Herzog,2007; Morrell et al., 2001; Wallace et al.,1998; Morrell et al.,1996; Morrell et al.,1994). No entanto, o conhecimento adquirido com as adultas tem sido extrapolado para as adolescentes, pressupondo-se que elas também sofram influência semelhante.

As adolescentes avaliadas neste estudo foram provenientes de um ambulatório de atendimento terciário. Entretanto, nota-se que, em concordância com os dados disponíveis para a população geral, foi obtida uma amostra com aproximadamente 70\% das pacientes com bom controle, em monoterapia exclusiva (Pedley et al.,2000). Quanto ao maior contingente de casos criptogênicos e idiopáticos, vale ressaltar o fato da maior ocorrência de síndromes generalizadas idiopáticas nesta faixa etária. A exclusão de pacientes com deficiência mental levou à exclusão da maior parte dos casos de epilepsia sintomática avaliados. 


\section{Função, comportamento e educação sexual}

Historicamente, adolescentes com doenças crônicas têm sido consideradas infantilizadas e inocentes, sem atividade sexual. Este conceito é extremamente controverso. Alguns estudos populacionais mostraram que os adolescentes com doenças crônicas têm vida sexual ativa (Choquet et al.,1997; Suris et al.,1996; Carroll et al.,1983). Sabe-se, entretanto, que doenças diferentes têm impacto distinto sobre

diferentes órgãos e sistemas e ao agrupar pacientes com doenças distintas sob a denominação de doenças crônicas, informações mais específicas podem ser perdidas. Os estudos em adolescentes com lúpus eritematoso sistêmico juvenil (LESJ), de Silva et al. (2002), ilustram este fato. Meninas com LESJ têm função gonadal preservada, enquanto meninos com LESJ apresentam altas taxas de disfunção gonadal. Nosso estudo demonstrou que adolescentes com epilepsia representam um grupo especial, pois a despeito de sua doença, têm vida sexualmente ativa, sendo que $51,4 \%$ das adolescentes referiram sua primeira relação sexual, e 37,1\% era sexualmente ativa no momento da entrevista. A freqüência da atividade sexual assim como a idade da primeira relação não diferiu de adolescentes sem doença crônica e não teve relação com variáveis clínicas relevantes da epilepsia como gravidade, freqüência de crises, tipo de epilepsia e uso de mono ou politerapia.

No que diz respeito à função sexual, embora na mulher com epilepsia haja diminuição de libido e satisfação sexual (Herzog,2007; Morrell et al., 2001; Morrell et al.,1996; Morrell et al.,1994), os dados encontrados nesse estudo sugerem que as adolescentes, a despeito da síndrome epiléptica, da freqüência de crises ou da terapêutica instituída, tenham a libido e a satisfação sexual preservadas. Diferentes fatores podem estar implicados na diferença observada entre adolescentes e mulheres com epilepsia. Primeiro, há a diferença que diz respeito às características inerentes a essa faixa etária, como a vivência temporal do adolescente ("aqui e agora") (Saito et 
al.,2000). Segundo, as adolescentes ainda não sofreram as conseqüências sociais e psicológicas impostas pela doença, como o estigma e o isolamento social, embora este já possa ocorrer em fases precoces da vida (Duchowny et al.,1998), sobretudo nas epilepsias com início na infância. Deve-se ainda enfatizar que o tempo de duração da doença, e, portanto o tempo de exposição à atividade epileptogênica e às DAE seja menor nas adolescentes, com preservação da função sexual.

O tamanho da amostra representa uma importante limitação deste estudo, impedindo que estes dados sejam generalizados para a população de adolescentes com epilepsia. Desta forma, mais estudos são necessários para confirmar nossos resultados. Outras limitações deste estudo dizem respeito à metodologia empregada para a avaliação dos aspectos relacionados à função sexual. Não há um consenso na literatura a respeito do melhor instrumento para tal avaliação. Muitos instrumentos foram desenvolvidos nos últimos anos, principalmente com propósitos de diagnóstico e tratamento das disfunções sexuais. No entanto, diferenças étnicas, educacionais ou culturais podem influenciar nos resultados destes testes. O desenvolvimento de um questionário para este estudo das adolescentes na população brasileira foi necessário pois uma limitação relacionada aos métodos disponíveis e validados é a de que a faixa etária estudada não inclui adolescentes (Derogatis et al.,2007;Sidi et al.,2007;Toledano et al.,2006;Rosen, 2002).

O perfil das adolescentes, que concordaram em participar do estudo, pode diferir das adolescentes que apesar de apesar de terem critérios para inclusão, recusaram-se a participar. É possível que as adolescentes que concordaram em participar sintam-se mais confortáveis em responder questões a respeito da sua experiência e comportamento sexuais. Por outro lado, uma possível limitação é a veracidade das respostas das adolescentes sobre o seu comportamento sexual. Como exemplo, a pergunta sobre masturbação que gera reações conflitantes entre as jovens. A masturbação carrega preconceitos que faz com que seja difícil, em especial 
no sexo feminino, admitir seu exercício tanto nas adolescentes com epilepsia como nas adolescentes sem doença crônica.

Neste estudo utilizamos um questionário auto-aplicável com garantia de total confidencialidade à adolescente. Estudos a respeito da sexualidade feminina sugerem que questionários geram respostas mais confiáveis do que entrevistas pessoais (Rosen et al.,1993).

Educação sexual - Neste estudo, observamos que a investigação sobre educação sexual demonstrou que as adolescentes com epilepsia, muitas vezes, obtêm informações não personalizadas, através de palestras na escola e utilizam métodos contraceptivos por conta própria, desconhecendo o impacto que sua doença ou as medicações que usam podem ter sobre sua função sexual e contracepção. A orientação através de programas educacionais direcionados, por exemplo, à prevenção do HIV e orientação sexual tem um papel relevante, contribuindo para o decréscimo da atividade sexual (Kirby et al.,2007). Portanto, a escola tem o potencial para reduzir o comportamento de risco das adolescentes. Entretanto, vale ressaltar que as informações obtidas através de fontes que abordem o tema de forma não individualizada, podem transmitir uma falsa sensação de segurança às adolescentes com doenças crônicas que iniciam sua vida sexual, fazendo com que as mesmas acreditem que tenham conhecimento suficiente para o início da sua atividade sexual, ignorando aspectos particularidades relacionadas à sua doença.

Um resultado deste trabalho é o de altos índices de gestação não planejada, a despeito do uso de contraceptivos relatado pelas pacientes entrevistadas. Corroborando este dado, Paniz et al. (2005),em um estudo populacional com 3542 indivíduos com idade superior a 15 anos, demonstrou que o uso de contraceptivos é elevado, porém o seu uso é incorreto e inadequado, sugerindo conhecimento escasso sobre os métodos. 
Apesar do contato freqüente com profissionais de saúde, as adolescentes relataram o uso não orientado de algum método contraceptivo, e as adolescentes que engravidaram relataram o uso do preservativo masculino, mas de forma inadequada, com conseqüente ruptura durante o ato sexual. $\mathrm{O}$ uso inadequado do contraceptivo hormonal também foi relatado, com uma gravidez no mês subseqüente à falha. $O$ termo "contracepção de emergência" era conhecido de $50 \%$ das pacientes, mas somente $20 \%$ admitiram saber como usá-la. Segundo Paniz et al.,70\% das mulheres entrevistadas não sabia como proceder no caso de esquecimento de um comprimido do contraceptivo oral.

Desta forma, observamos um dado contraditório em relação a estas pacientes. Embora, as adolescentes com epilepsia tenham maior acesso a médicos que as adolescentes sem doença crônica, nossos resultados demonstraram a falta de orientação adequada. Postulamos que este fato seja decorrente de pelo menos dois fatores. Primeiro, a suposição de que pacientes com doenças crônicas não sejam sexualmente ativas (Neinstein, 2001; Carroll et al.,1983). Outro possível fator contribuitório é a de que o médico de seguimento da epilepsia não assume a educação sexual ou a referência para um profissional habilitado como sua atribuição. Para os profissionais de saúde e os cuidadores, o mais importante é o controle de crises e a redução dos efeitos colaterais das drogas antiepilépticas (Devinsky et al.,1999; Slevin et al.,1988).

Como demonstrado em nosso estudo, as adolescentes com epilepsia sofrem muitas conseqüências do exercício não orientado da sua sexualidade, como gestações não planejadas, que será discutido a seguir.

Gestação - A taxa de gestação na nossa população é estatisticamente superior a adolescentes sem doença crônica. A gravidez nas pacientes com epilepsia pode levar a piora no número de crises, além dos riscos de teratogenicidade das DAE e da probabilidade maior da ocorrência de complicações obstétricas. Entretanto, as 
pacientes desconhecem tais riscos, e não estão devidamente prevenindo os riscos de malformação fetal com o uso crônico de ácido fólico. As altas taxas de gravidez indesejada encontradas neste estudo corroboram os dados obtidos por Wirrell et al.,em 1997.

Em nosso estudo, foi observada uma taxa de $33,3 \%$ da piora das crises epilépticas durante a gestação, sendo que em dois casos houve ocorrência de crises TCG. Houve um caso de abortamento induzido, e outro no qual as informações a respeito das circunstâncias em que o aborto ocorreu foram negadas pela paciente. Essas situações demonstram a exposição das adolescentes a riscos que poderiam ser minimizados com a orientação adequada.

As adolescentes que planejaram a gestação consideraram como planejamento o desejo de engravidar, sem conhecimento sobre a doença ou contato com profissional da área de saúde previamente à gestação em andamento. Mesmo após a orientação dada às pacientes grávidas que iniciavam o seguimento neurológico no ambulatório, a respeito dos riscos enfrentados sem um acompanhamento adequado, foi observada uma taxa de abandono do seguimento de cerca de $38 \%$. Nos casos de pacientes que já haviam engravidado e tido crianças saudáveis, notou-se uma falsa sensação de segurança quanto à futura gravidez, com base apenas no êxito anterior.

A presença de um número elevado de adolescentes gestantes neste estudo pode ser decorrente de múltiplos fatores. Um fator relevante é de que houve diferença entre as adolescentes com epilepsia e o grupo controle quanto ao nível socioeconômico, embora sem significância estatística, o que pode implicar em diferenças quanto à educação sexual recebida por essas jovens. Um segundo fator, é a de que o estigma da epilepsia leve o profissional de saúde, pais e cuidadores e até mesmo as próprias pacientes a acreditar na própria incapacidade em gerar filhos e, conseqüentemente, ignorar questões relacionadas à função sexual e gonadal. Esta última hipótese é corroborada pelo nosso estudo (Vincentiis et al.,submitted) que 
avaliou 75 adolescentes, 52 com lúpus eritematoso sistêmico juvenil (LESJ), uma doença visível e debilitante, mas sem estigma, e 23 adolescentes com epilepsia. Não houve diferença estatisticamente significante entre a idade da primeira relação sexual nos dois grupos, mas as adolescentes com LESJ relataram libido e orgasmo diminuídos, provavelmente relacionados à doença de base. Porém, as adolescentes com epilepsia apresentaram maiores taxas de gravidez indesejada, mesmo com índices semelhantes de uso de contraceptivos.

Não podemos excluir, ainda, um possível viés de referência das adolescentes para o estudo. Ainda assim, este estudo corrobora a necessidade premente de que os profissionais de saúde envolvidos no cuidado de adolescentes com doença crônica estejam alerta quanto às necessidades especiais deste grupo (Rew, 2006; Murphy, 2005).

Portanto, os aspectos relacionados à função sexual, comportamento sexual e contracepção requerem atenção especial por parte dos profissionais de saúde que atendem adolescentes com epilepsia.

\section{Função Gonadal}

Parâmetros Metodológicos: A ausência de um exame específico para a avaliação da função gonadal em adolescentes e dúvidas em relação à sensibilidade de cada exame na literatura fez com que adotássemos uma metodologia mais ampla. Os parâmetros escolhidos neste estudo são reconhecidos como evidências diretas ou indiretas de ovulação (Jaffe et al., 1991).

Os parâmetros clínicos utilizados neste estudo foram: ciclos menstruais normais com ou sem dismenorréia. Os parâmetros laboratoriais foram a USG pélvica (Amso et al.,2005; Ferreira et al.,2001) e dosagens hormonais, enfatizando os níveis de progesterona sérica durante a fase lútea e FSH na fase folicular (Bowen et al.,2007; 
van der Steeg et al.,2007; Ferreira et al.,2001; Scott et al.,1995). A presença de gravidez prévia (inferior a seis meses), na admissão ou durante o estudo foi adotada como o único parâmetro direto de função gonadal normal.

A adoção de um protocolo mais amplo, com necessidade de diversas visitas ao hospital, bem como a necessidade de um acompanhante no caso de adolescentes com idade inferior a 18 anos, dificultou a adesão ao protocolo limitando o número de pacientes que participou desta fase do estudo.

Embora as alterações relacionadas ao ciclo menstrual não fossem um objetivo primário deste trabalho, foram tão relevantes que serão discutidas separadamente.

Menarca: A idade média da ocorrência da menarca é de $12,5 \pm 1,3$ ano na população brasileira (Colli, 1988). Não foi observada diferença estatisticamente significante entre a idade da menarca das adolescentes com epilepsia e o grupo controle. No entanto, neste estudo, foi observado que as adolescentes em uso de VPA na época da menarca apresentaram a menarca mais precocemente.

Não existe mecanismo único capaz de explicar, de modo convincente, como se processa o amadurecimento sexual que, de modo mais definido, se manifesta com os fenômenos pubertários, com estabelecimento da atividade do eixo hipotálamohipófise-gonadal. Acredita-se que durante a infância há refratariedade hipotalâmica aos esteróides circulantes. Essa refratariedade decresce com o passar dos anos e a maior sensibilidade aos esteróides circulantes daria início aos fenômenos pubertários com influência recíproca do sistema nervoso central (SNC) e glândulas. Hoje se acredita que o marcador da liberação adequada de gonadotrofinas seja os ovários (Giordano, 2001). O ovário é responsável pela síntese de peptídeos (células da teca e granulosa), que exercem efeito tanto na própria célula de origem (efeito autócrino) como nas células estruturalmente semelhantes e próximas (efeito parácrino), controlando também a secreção da glândula à distância (efeito hormonal), como na hipófise (Giordano,2001). A presença de estrógenos e andrógenos circulantes numa 
época precoce da vida reveste-se de grande importância, uma vez que leva a uma ativação dos receptores dos chamados órgãos alvo, com conseqüente desenvolvimento e maturação (Barros,2001).

O VPA inibe as enzimas do citocromo P450, aumentando a concentração dos esteróides circulantes (Isojarvi, 2007; Murialdo et al., 1998; Isojarvi et al.,1993). A hiperinsulinemia de jejum, com conseqüente hipoglicemia, induzida pelo uso crônico de VPA, é associada à obesidade, o que pode levar a hiperestimulação dos ovários (Isojarvi,2007; Pylvanen et al., 2006; Morrell et al.,2002; Isojarvi et al.,1996). Portanto, uma hipótese para a antecipação da menarca nessas pacientes seria o aumento de esteróides circulantes em decorrência do uso de VPA, levando ao desenvolvimento e maturação em fases mais precoces da vida.

Houve ainda uma correlação entre menarca mais precoce e controle inadequado de crises, a despeito da síndrome epiléptica e da presença ou não de lesão estrutural. Segundo Klein e Herzog (1998), uma das explicações para a disfunção de natureza endócrina nas mulheres com epilepsia é a influência direta da lesão epileptogênica ou da epilepsia nos centros de controle endócrino do cérebro (eixo hipotálamo-hipofisário). Em concordância com estes autores, acreditamos que a antecipação da menarca nestas pacientes pode representar a influência das crises epiléptica sobre o eixo hipotálamo-hipofisário, em fases precoces da vida.

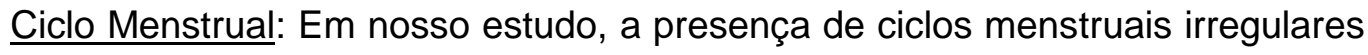
foi um dado relevante, ocorrendo em 14 pacientes, caracterizados por ciclos irregulares e com intervalo mais prolongado; em três dessas pacientes, foi relatado também um aumento na duração e intensidade do fluxo menstrual, com diferença estatisticamente significante com relação ao grupo controle.

Durante os primeiros 12 a 18 meses após a menarca, a duração dos ciclos menstruais é freqüentemente prolongada e irregular, como resultado do desenvolvimento folicular inadequado e ciclos anovulatórios (Spritzer et al., 2001). Das 
14 pacientes que relataram ciclos irregulares, três se encontravam dentro do primeiro ano pós-menarca. Portanto, a idade das pacientes pode ter sido um fator contribuitório, mas não o único, para explicar ciclos irregulares.

Em nosso estudo observamos que a presença de TCG, independentemente da síndrome epiléptica, da freqüência de crises e da terapêutica instituída, correlacionouse com a irregularidade menstrual observada em algumas pacientes. As crises TCG provocam aumentos transitórios de prolactina sérica, o que pode correlacionar-se às alterações menstruais. Embora o mecanismo pelo qual a hiperprolactinemia acarrete os distúrbios menstruais não esteja completamente esclarecido, supõe-se que a hiperprolactinemia leve à supressão da pulsatilidade da secreção de gonadotrofinas, pois sua elevação leva à elevação da dopamina hipotalâmica, a qual por sua vez, tem também efeito inibidor sobre o hormônio liberador de gonadotrofinas $(\mathrm{GnRH})$, ocasionando diminuição do FSH e do LH, com conseqüente irregularidade menstrual, insuficiência lútea, anovulação e amenorréia. (Giordano,2001). Ao contrário dos achados de Herzog et al.(2001,1986) em mulheres com epilepsia, não foi observada influência da síndrome epiléptica, sobretudo da epilepsia do lobo temporal, na irregularidade menstrual encontrada nas adolescentes com epilepsia.

Outro fator relacionado à presença de ciclos irregulares foi o tempo de duração da doença. Mulheres com epilepsia têm maior risco para desenvolver distúrbios menstruais do que mulheres na população geral (Herzog, 2007,2006), incluindo amenorréia, oligomenorréia, ciclos menstruais mais longos ou mais curtos que o normal, e ciclos anovulatórios (Herzog, 2007;Morrell et al.,2002). Amenorréia, freqüentemente relatada em mulheres adultas com epilepsia (Herzog,2007;Morrell et al.,2002), não foi observada nestas pacientes.

Desta forma, estes dados em adolescentes reforçam a idéia de que estejamos frente a um processo em evolução. O seguimento destas pacientes, que faz parte da continuidade deste trabalho, poderá confirmar estes achados. 
Função Gonadal: Os resultados obtidos neste estudo com a avaliação de função gonadal sugerem que, durante a adolescência, as pacientes tenham sua função gonadal preservada.

As treze pacientes que já haviam engravidado foram consideradas férteis no momento da avaliação. Não foi observada correlação estatisticamente significante entre as variáveis clínicas da epilepsia, como a síndrome epiléptica, freqüência de crises e a terapêutica instituída quanto a índices de gravidez e abortamentos.

A dismenorréia primária (com ausência de patologia subjacente) costuma apresentar-se nos primeiros 6-12 meses após a menarca, quando os ciclos ovulatórios são estabelecidos (Herter, 2001). Em 24 pacientes, foi relatada a presença de dismenorréia primária. Embora, esta seja um forte indicador de ciclo ovulatório, as paciente que não tinham dados laboratoriais, somente foram consideradas como tendo dados clínicos sugestivos de função gonadal normal, caso apresentassem dismenorréia e ciclos menstruais regulares.

As duas gonadotrofinas hipofisárias, o FSH e o LH, em equilíbrio dinâmico com o estradiol estabelecem os caminhos fisiológicos através dos quais se define a normalidade da função menstrual (Linhares, 2001). O FSH é um marcador da reserva ovariana. No estudo de van der Steeg et al. (2007), níveis basais de FSH (dosagem realizada no $3^{\circ}$. dia do ciclo menstrual) de $8 \mathrm{UI} / \mathrm{L}$ ou superiores correlacionaram-se com disfunção gonadal.

No processo de esteroidogênese, a progesterona é o primeiro esteróide hormonal de maior significado, originando-se caracteristicamente no corpo lúteo e na placenta (Linhares, 2001). Portanto, níveis normais de progesterona são o maior indicativo de um corpo lúteo atuante, levando ao diagnóstico indireto de ovulação, exceto nos casos (raros) em que há luteinização do folículo íntegro, com o óvulo enclausurado (Linhares, 2001). A disfunção de fase lútea é caracterizada por uma fase lútea curta ou inadequada, com diminuição da secreção de progesterona (Linhares, 
2001). A disfunção lútea ocorre em $5 \%$ das mulheres inférteis. Entretanto, pode também ser observada nos primeiros meses após a menarca, ou mesmo esporadicamente em mulheres férteis. (Linhares, 2001).

Portanto, enquanto a produção de progesterona e a demonstração de folículo ovariano pelo ultra-som são indicadores de um ciclo fértil, o FSH é um indicador de reserva folicular normal, ou seja, de capacidade reprodutora preservada, mesmo na presença de um ciclo sem ovulação. Seis das nossas pacientes, consideradas férteis pelos parâmetros clínicos, apresentaram níveis de FSH normais. Uma destas pacientes apresentava níveis de progesterona anormal com ultra-som demonstrando ausência de ovulação naquele ciclo. A demonstração de níveis de FSH normais demonstra reserva folicular adequada com um ciclo anovulatório e, portanto, esta paciente pode ser considerada preservada.

Este estudo sugere que as pacientes tenham sua função gonadal preservada. No entanto, as irregularidades menstruais encontradas podem sugerir que durante a vida adulta estas jovens irão experimentar as conseqüências já descritas para a mulher adulta com epilepsia, no que diz respeito à sua função gonadal. Portanto, abrese uma perspectiva futura de estudos com maior número de pacientes, para a determinação de sua função gonadal e seu seguimento.

Portanto, os profissionais de saúde envolvidos no cuidado dessas pacientes devem estar alerta quanto a essas complicações potenciais da epilepsia e suas conseqüências para a mulher em idade fértil. 
Conclusões 
1. Adolescentes com epilepsia apresentaram comportamento sexual similar ao observado em adolescentes sem doenças crônicas.

2. Adolescentes com epilepsia apresentaram evidências clínicas e, por vezes, laboratoriais de função gonadal preservada.

3. Adolescentes com epilepsia apresentaram idade da menarca similar aos controles, entretanto tiveram maior número de ciclos menstruais irregulares, com número maior de dias e intervalo superior ao observado em adolescentes sem doenças crônicas.

4. Neste estudo, adolescentes com epilepsia não receberam educação sexual adequada, apresentando freqüência de gestação superior aos controles.

5. Os diferentes aspectos da função e comportamento sexual não estiveram relacionados com as variáveis da epilepsia.

6. Menarca mais precoce foi mais freqüente em adolescentes com epilepsia que estavam em uso de valproato na época da menarca e que apresentavam controle irregular e insatisfatório das suas crises epilépticas.

7. Ciclos menstruais irregulares foram mais freqüentes em adolescentes com epilepsia com duração mais longa da doença e ocorrência de crises TCG, independentemente da síndrome epiléptica ou da terapêutica instituída. 
Este projeto contou com o apoio financeiro da FAPESP

Processo 05/03527-3 


\section{Referências Bibliográficas*}

${ }^{*}$ De acordo com:

UNIVERSIDADE DE SÃO PAULO. Faculdade de Medicina. Serviço de Biblioteca e Documentação. Estrutura e apresentação de dissertações e teses. Elaborado por Anneliese Carneiro da Cunha, São Paulo, Serviço de Biblioteca e Documentação, 1996.

Abreviaturas dos títulos dos periódicos de acordo com LIST OF JOURNALS INDEXED IN INDEX MEDICUS. 
1. Almeida PM; Wickerhauser $\mathrm{H}$ : Critério ABA (Associação Brasileira de Anunciantes) e Abipeme (Associação Brasileira dos Institutos de Pesquisa de Mercado), São Paulo, 1991, p. 1-29.

2. Amso NN; Griffiths A. The role and applications of ultrasound in ambulatory gynaecology. Best. Pract. Res. Clin. Obstet. Gynaecol. 2005 Aug;19(5):693-711.

3. Austin JK; Huster GA; Dunn DW, et al. Adolescents with active or inactive epilepsy or asthma: a comparison of quality of life. Epilepsia 1996;37:1228-38.

4. Artama M; Isojarvi Jl; Auvinen A. Antiepileptic drug use and birth rate in patients with epilepsy--a population-based cohort study in Finland. Hum. Reprod. 2006 Sep;21(9):2290-5.

5. Bagley C; Bolitho F; Bertrand L. Norms and construct validity of the Rosemberg self-esteem scale in Canadian high school populations: implications for counseling.

Can. J. Counseling 1997; 31:82-92.

6. Barros RCR. Puberdades precoce e tardia. In: Oliveira HC e Lemgruber I, eds. Tratado de ginecologia da FEBRASGO, $1^{\text {a }}$ ed (reimpressão). Rio de Janeiro: REVINTER livraria e editora, 2001:323-339.

7. Beier KM.[Biopsychosocial understanding of human sexuality. Prerequisite for diagnostics and treatment in sexual medicine] Urologe A. 2006 Aug;45(8):953-4, 956-9.

8. Biton V ; Mirza W ; Montouris G, et al. Weight change associated with valproate and lamotrigine monotherapy in patients with epilepsy. Neurology 2001; 56:172177.

9. Bowen S; Norian J; Santoro N, et al. Simple tools for assessment of ovarian reserve (OR): individual ovarian dimensions are reliable predictors of OR. Fertil. Steril. 2007 Aug;88(2):390-5.

10. Carroll G; Massarelli E; Opzoomer A, et al. Adolescents with chronic disease: are they receiving comprehensive health care? J. Adolesc. Health 1983;4:261-265. 
11. Choquet M; Fediaevsky L; Manfredi R. Sexual behavior among adolescents reporting chronic conditions: A French national survey. J. Adolesc. Health $1997 ; 20: 62-67$

12. Colli AS. Crescimento e Desenvolvimento Pubertário em Crianças e Adolescentes Brasileiras. Editora Brasileira de Ciências Ltda; São Paulo,1988,165.

13. Derogatis L; Clayton A; Lewis-D'Agostino D, et al. Validation of the Female Sexual Distress Scale-Revised for Assessing Distress in Women with Hypoactive Sexual Desire Disorder. J. Sex. Med. 2007 Nov 27(In press).

14. Devinsky O; Vuong A; Hammer A, et al. Stable weight during lamotrigine therapy: a review of 32 studies. Neurology 2000; 54:973-975.

15. Devinsky O; Westbrook L; Cramer J, et al. Risk factors for poor health-related quality of life in adolescents with epilepsy. Epilepsia 1999; 40:1715-1720.

16. Deslypere JP; Verdonck L; Vermeulen A. Fat tissue: a steroid reservoir and site of endocrine metabolism. J. Clin. Endocrinol. Metab. 1985;61:564-570.

17. Dodson WE. Efficacy. In: Engel Jr J, Pedley TA, eds. Epilepsy: a comprehensive CD-ROM. Philadelphia: Lippincott Williams and Wilkins, 1999:18550-18742.

18. Duchowny M; Valente KDR; Valente $M$, et al. Cirurgia de epilepsia na infância. In: Costa JC, Palmini A, Yacubian EMT, Cavalheiro EA, eds. Fundamentos neurobiológicos das epilepsias: aspectos clínicos e cirúrgicos. São Paulo: Lemos-Editorial, 1998:1059-1103.

19. Engel Jr J; International League Against Epilepsy (ILAE). A proposed diagnostic scheme for people with epileptic seizures and with epilepsy: report of the ILAE Task Force on Classification and Terminology. Epilepsia 2001 Jun;42(6):796-803.

20. Engel Jr J; Pedley TA. Introduction: What is Epilepsy? In: Engel Jr J, Pedley TA, eds. Epilepsy: a comprehensive CD-ROM. Philadelphia: Lippincott Williams and Wilkins, 1999:1728-1797. 
21. Fernandez-Guasti A; Escalante A; Agmo A. Inhibitory action of various 5-HT1B receptor agonists on rat masculine sexual behavior. Pharmacol. Biochem. Behav. 1989;34:811-816.

22. Ferreira JAS; Wehba S. Avaliação do eixo hipotálamo-hipófise-ovário. In: Oliveira HC e Lemgruber I, eds. Tratado de ginecologia da FEBRASGO, $1^{\text {a }}$ ed (reimpressão). Rio de Janeiro: REVINTER livraria e editora, 2001:237-243.

23. Foldvary N. Treatment of epilepsy during pregnancy. In: Wyllie E, ed. Treatment of epilepsy: principles and practice, $3^{\mathrm{a}}$ ed. Baltimore: Lippincott Williams \& Wilkins, 2001:775-786.

24. Giacobbe M; Pastore AR. Infância e adolescência. In: Pastore AR, Cerri GG (eds). Ultra-sonografia. Obstetrícia e Ginecologia. Sarvier: São Paulo, 1997:631-637.

25. Giordano MG. Bases biológicas: fisiologia. In: Oliveira HC e Lemgruber I, eds. Tratado de ginecologia da FEBRASGO, $1^{\underline{a}}$ ed (reimpressão). Rio de Janeiro: REVINTER livraria e editora, 2001:29-47.

26. Gomes M; Zeitoune RG; Kropf LA, et al.. A house-to-house survey of epileptic seizures in an urban community of Rio de Janeiro, Brazil. Arq. Neuropsiquiatr. 2002 Sep;60(3-B):708-11.

27. Hagborg WJ. The Rosemberg self-esteem scale and Harter's self perception profile for adolescents: a concurrent validity study. Psychol Schools 1993; 30: $132-6$.

28. Hauser WA. Incidence and Prevalence In: Engel Jr J, Pedley TA, eds. Epilepsy: a comprehensive CD-ROM. Philadelphia: Lippincott Williams and Wilkins, 1999:2154-2323.

29. Herter LD. Disfunção menstrual na puberdade-amenorréia, dismenorréia, tensão pré-menstrual.In: Oliveira HC e Lemgruber I, eds. Tratado de ginecologia da FEBRASGO, $1^{\text {a }}$ ed (reimpressão). Rio de Janeiro: REVINTER livraria e editora, 2001:314-322. 
30. Herzog AG. Disorders of reproduction in patients with epilepsy: Primary neurological mechanisms. Seizure 2007 Dec 28 (In press).

31. Herzog AG. Disorders of reproduction and fertility. In: Engel J, Pedley TA, eds. Epilepsy: a comprehensive textbook. Philadelphia: Lippincott-Raven, 1997:2013-2026.

32. Herzog AG. Menstrual disorders in women with epilepsy. Neurology 2006 Mar 28;66(6 Suppl 3):S23-8.

33. Herzog AG; Fowler KM. Sexual hormones and epilepsy: threat and opportunities. Curr. Opin. Neurol. 2005 Apr;18(2):167-72.

34. Herzog AG; Friedman M. Menstrual cycle interval and ovulation in women with localization-related epilepsy. Neurology 2001; 57:2133-2135.

35. Herzog AG; Schachter SC. Valproate and the polycystic ovarian syndrome: final thoughts. Epilepsia 2001; 42:311-315.

36. Herzog AG; Seibel MM; Schomer DL, et al. Reproductive endocrine disorders in women with partial seizures of temporal lobe origin. Arch. Neurol.1986; 43:347350.

37. Hitiris N; Brodie MJ. Modern antiepileptic drugs: guidelines and beyond. Curr. Opin. Neurol. 2006 Apr;19(2):175-80.

38. Isojärvi J. Disorders of reproduction in patients with epilepsy: Antiepileptic drug related mechanisms. Seizure 2007 Dec 26 (In press)

39. Isojärvi JIT; Laatikainen TJ; Knip M, et al. Obesity and endocrine disorders in women taking valproate for epilepsy. Ann. Neurol.1996; 39:579-584.

40. Isojärvi JIT; Laatikainen TJ; Pakarinen AJ, et al. Polycystic appearing ovaries and hyperandrogenism in women taking valproate for epilepsy. N. Engl. J. Med .1993; 329:1383-1388.

41. Isojärvi JIT; Rättyä J; Myllylä VV, et al. Valproate, lamotrigine and insulin mediated risks in women with epilepsy. Ann. Neurol. 1998; 43:446-451. 
42. Isojarvi Jl; Tauboll E; Herzog AG. Effect of antiepileptic drugs on reproductive endocrine function in individuals with epilepsy. CNS Drugs. 2005;19(3):207-23.

43. Jaffe SB; Jawelewicz R. The basic infertility investigation. Fertil. Steril.1991;56:599.

44. Jessor R. Risk behavior in adolescence: a psychosocial framework for understanding and action. J. Adolesc. Health 1991;12:597-605.

45. Kirby DB; Laris BA; Rolleri LA. Sex and HIV education programs: their impact on sexual behaviors of young people throughout the world. J. Adolesc. Health 2007 Mar;40(3):206-17.

46. Klein P; Herzog AG. Hormonal effects on epilepsy in women. Epilepsia 1998; 39(Suppl 8): S9-S16.

47. Klein P; Serje A; Pezzullo JC. Premature ovarian failure in women with epilepsy. Epilepsia 2001 Dec;42(12):1584-9.

48. Lach LM; Ronen GM; Rosenbaum PL, et al. Health-related quality of life in youth with epilepsy: theoretical model for clinicians and researchers. Part I: the role of epilepsy and co-morbidity. Qual. Life Res. 2006 Sep;15(7):1161-71.

49. Laumann EO; Paik A; Rosen RC. Sexual dysfunction in the United States, prevalence and predictors. JAMA 1999;281:537-44.

50. Lee GP ; Park YD ; Clason CL, et al. Disparate views of health-related quality of life between adolescents with epilepsy and their parents. Epilepsia 2006;47(Suppl 4):111.

51. Linhares E. Dosagens hormonais em Ginecologia. In: Oliveira HC e Lemgruber I, eds. Tratado de ginecologia da FEBRASGO, $1^{\text {a }}$ ed (reimpressão). Rio de Janeiro: REVINTER livraria e editora, 2001:29-47.

52. Liporace J; D’Abreu A . Epilepsy and women's health: family planning, bone health, menopause, and menstrual-related seizures. Mayo Clin. Proc. 2003; 78:497-506. 
53. Lofgren E; Mikkonen K; Tolonen U, et al. Reproductive endocrine function in women with epilepsy: The role of epilepsy type and medication. Epilepsy Behav. 2007 Feb;10(1):77-83.

54. Marino Jr. R; Cukiert A; Pinho E. Epidemiological aspects of epilepsy in Sao Paulo: a prevalence study. Arq. Neuropsiquiatr. 1986 Sep;44(3):243-54.

55. Mattson $\mathrm{RH}$; Cramer JA; Collins JF, et al. Comparison of carbamazepine, phenobarbital, phenytoin and primidone in partial and secondarily generalized tonic-clonic seizures. N. Engl. J. Med. 1985;313:145-151.

56. Mikkonen K; Vainionpaa LK; Pakarinen AJ, et al. Long-term reproductive endocrine health in young women with epilepsy during puberty. Neurology 2004 Feb 10;62(3):445-50.

57. Morrell MJ. Catamenial epilepsy and issues of fertility, sexuality, and reproduction. In: Wyllie E, ed. Treatment of epilepsy: principles and practice, $3^{\mathrm{a}}$ ed. Baltimore: Lippincott Williams \& Wilkins, 2001:671-680.

58. Morrell MJ. Effects of epilepsy on women's reproductive health. Epilepsia 1998; 39(Suppl 8):S32-37.

59. Morrell MJ; Flynn KL; Done S, et al. Sexual dysfunction, sex steroid hormone abnormalities, and depression in women with epilepsy treated with antiepileptic drugs. Epilepsy Behav. 2005 May;6(3):360-5.

60. Morrell MJ; Flynn KL; Seale CG, et al. Reproductive dysfunction in women with epilepsy: antiepileptic drug effects on sex-steroid hormones. CNS Spectrums $2001 ; 6: 771-785$.

61. Morrell MJ; Giudice L; Flynn KL, et al. Predictors of ovulatory failure in women with epilepsy. Ann. Neurol. 2002; 52:704-711.

62. Morrell MJ; Guldner GT. Self-reported sexual function and sexual arousability in women with epilepsy. Epilepsia 1996;37:1204-1210. 
63. Morrell MJ; Montouris GD. Reproductive disturbances in patients with epilepsy. Cleve. Clin. J. Med. 2004 Feb;71 Suppl 2:S19-24.

64. Morrell MJ; Sperling MR; Stecker M, et al.Sexual dysfunction in partial epilepsy: a deficit in physiological sexual arousal. Neurology 1994; 44:243-247.

65. Murialdo G; Galimbeti CA; Gianelli MV, et al. Effects of valproate, phenobarbital, and carbamazepine on sex steroid setup in women with epilepsy. Clin. Neuropharmacol. 1998; 21:52-58.

66. Murphy N. Sexuality in children and adolescents with disabilities. Dev. Med. Child Neurol. 2005;47(9):640-4.

67. Neinstein LS. The treatment of adolescents with a chronic illness. West. J. Med. $2001 ; 175: 293-295$.

68. Paniz VMV; Fassa AG; Silva MC. Conhecimento sobre anticoncepcionais em uma população de 15 anos ou mais de uma cidade do Sul do Brasil. Cad. Saúde Pública 2005;21(6):1747-60.

69. Paredes RG; Manero MC; Haller AE, et al. Sexual behavior enhances postictal behavioral depression in kindled rats: opioid involvement. Behav. Brain Res. 1992;52:175-182.

70. Pasquali R; Cassimirri F. The impact of obesity on hyperandrogenism and polycystic ovary syndrome in premenopausal women. Clin. Endocrinol. 1993;39:1-16.

71. Pedley TA; Bazil CW; Morrell MJ. Epilepsy. In: Rowland LP, ed. Merritt's Neurology, $10^{\text {th }}$ ed. Philadelphia: Lippincott Williams and Wilkins, 2000:813-832.

72. Perucca E. Birth defects after prenatal exposure to antiepileptic drugs. Lancet Neurol. 2005;4:781-86.

73. Proposal for revised classification of epilepsies and epileptic syndromes. Commission on Classification and Terminology of the International League Against Epilepsy. Epilepsia 1989 Jul-Aug;30(4):389-99. 
74. Pylvanen V; Pakarinen A; Knip M; Isojarvi J. Characterization of insulin secretion in Valproate-treated patients with epilepsy. Epilepsia 2006 Sep;47(9):1460-4.

75. Rew L. Sexual health promotion in adolescents with chronic health conditions. Fam. Community. Health 2006 ;29(1 Suppl):61S-9S.

76. Rosen RC. Assessment of female sexual dysfunction: review of validated methods. Fertil. Steril. 2002 Apr;77 Suppl 4:S89-93.

77. Rosen RC; Taylor JF; Leiblum SR, et al. Prevalence of sexual dysfunction in women: results of a survey study of 329 women in an outpatient gynecologic clinic. J. Sex. Marital. Ther. 1993;19:171-88.

78. Saito MI, Leal MM: Sexualidade e educação sexual. In Sucupira ACSL, Bricks LF, Kobinger MEBA, Saito MI, Zucculotto SMC: Pediatria em Consultório, 4ª ed, São Paulo, Sarvier, 2000, p. 720-730.

79. Sidi H; Abdullah N; Puteh SE, et al. The Female Sexual Function Index (FSFI): validation of the Malay version. J. Sex. Med. 2007 Nov;4(6):1642-54.

80. Schupf N; Ottman R. Likelihood of pregnancy in individuals with idiopathic/cryptogenic epilepsy: social and biologic influence. Epilepsia 1994;35:750-756.

81. Schupf N; Ottman R. Reproduction among individuals with idiopathic/cryptogenic epilepsy: risk factors for reduced fertility in marriage. Epilepsia 1996; 37:833-840.

82. Scott RT, Hofman GE. Prognostic assessment of ovarian reserve. Fertil. Steril.1995; 63:7-11.

83. Silva CA; Hallak J; Pasqualotto FF, et al. Gonadal function in male adolescents and young males with juvenile onset systemic lupus erythematosus. J. Rheumatol. 2002; 29: 2000-2005.

84. Silva CAA; Leal MM; Campos LMMA, et al. Aspectos da sexualidade e gravidez de adolescentes e adultos jovens com lúpus eritematoso sistêmico juvenil (LES). Rev. Bras. Reumatol. 2001; 41:213-219. 
85. Silva CA; Leal MM; Leone C, et al. Gonadal function in adolescents and young women with juvenile systemic lupus erythematosus. Lupus 2002; 11:419-425.

86. Shafer P. Counseling women with epilepsy. Epilepsia 1998; 39(Suppl 8): S38S44.

87. Slevin MB; Plant H; Lynch $\mathrm{D}$, et al. Who should measure quality of life, the doctor or the patient? Br. J. Cancer 1988; 57:109-12.

88. Souza MCB. Epidemiologia da infertilidade. In: Oliveira HC e Lemgruber I, eds. Tratado de ginecologia da FEBRASGO, $1^{\underline{a}}$ ed (reimpressão). Rio de Janeiro: REVINTER livraria e editora, 2001:481-482.

89. Spector IP; Carey MP. Incidence and prevalence of sexual dysfunctions: a critical review of the empirical literature. Arch. Sex. Behav. 1990;19:389-408.

90. Spritzer PM; Mallmann ES.Ciclo menstrual. Bastos AC. Aspectos evolutivos do aparelho reprodutor. In: Oliveira HC e Lemgruber I, eds. Tratado de ginecologia da FEBRASGo, $1^{\text {a }}$ ed (reimpressão). Rio de Janeiro: REVINTER livraria e editora, 2001:231-236.

91. Stevanovic D. Health-related quality of life in adolescents with well-controlled epilepsy. Epilepsy Behav. 2007 Jun;10(4):571-5.

92. Suris $\mathrm{J}$; Resnik M ; Cassuto N, et al. Sexual behavior of adolescents with chronic disease and disability. J. Adolesc. Health 1996;19:124-131.

93. Sweeting H. Reversals of fortune? Sex differences in health in childhood and adolescence. Soc. Sci. Med. 1995;40:77-90.

94. Taubøll E, Røste LS, Svalheim S, et al. Disorders of reproduction in epilepsy-What can we learn from animal studies?Seizure 2007 Dec 21(In press).

95. Tettenborn B. Management of epilepsy in women of childbearing age: practical recommendations. CNS Drugs 2006;20(5):373-87.

96. Tran TA. Premature ovarian failure in women with epilepsy. Epilepsia 2006;47(Suppl 4):7. 
97. Toledano R; Pfaus J. The sexual arousal and desire inventory (SADI): A multidimensional scale to assess subjective sexual arousal and desire. J. Sex. Med. 2006;3:853-877.

98. Valencia LS; Cromer BA. Sexual activity and other high-risk behaviors in adolescents with chronic illness: a review. J. Pediatr. Adolesc. Gynecol. 2000; $13: 53-64$

97. Van der Lugt PJ. Is an application form useful to select patients with epilepsy who may drive? Epilepsia 1975; 16:743-6.

98. Van der Steeg JW; Steures P; Eijkemans MJ, et al. Predictive value and clinical impact of basal follicle-stimulating hormone in subfertile, ovulatory women. J. Clin. Endocrinol. Metab. 2007 Jun;92(6):2163-8.

99. Vincentiis S, Silva CAA, Saito MI, et al. A sexualidade e a fertilidade na mulher e na adolescente com epilepsia: analogias e diferenças. J. Epilepsy Clin. Neurophysiol .2004; 10(4):205-211.

100. Wallace H; Shorvon S; Tallis R. Age-specific incidence and prevalence rates of treated epilepsy in an unselected population of 2.052 .922 and age-specific fertility rates of women with epilepsy. Lancet 1998; 352:1970-1973.

101. Wikipedia,The Free Encyclopedia. Wikimedia Foundation, Inc. Disponível em http://en.wikipedia.org/wiki/Human_sexual_behavior.

102. Wirrell EC; Camfield CS; Camfield PR, et al. Long-term psychosocial outcome in typical absence epilepsy. Sometimes a wolf in sheeps' clothing. Arch. Pediatr. Adolesc. Med. 1997 Feb;151(2):152-8.

103. Wong J; Wirrell E. Physical activity in children/teens with epilepsy compared with that in their siblings without epilepsy. Epilepsia 2006 Mar;47(3):631-9.

104. World Health Organization - Programmes and projects - Mental health $\begin{array}{lllll}\text { Neurology and public health. Disponível em } & \end{array}$ www.who.int/mental health/neurology/epilepsy 
105. Yerby MS. Clinical care of pregnant women with epilepsy: neural tube defects and folic acid supplementation. Epilepsia 2003; 44(Suppl 3):33-40.

106. Yerby MS and Collins SD. Pregnancy and the mother. In: Engel $\mathrm{J}$ and Pedley TA, eds. Epilepsy: a comprehensive textbook. Philadelphia: Lippincott-Raven Publishers; 1997:2027-2035. 


\title{
HOSPITAL DAS CLÍNICAS
}

\author{
DA \\ FACULDADE DE MEDICINA DA UNIVERSIDADE DE SÃO PAULO
}

\section{TERMO DE CONSENTIMENTO LIVRE E ESCLARECIDO}

Sabemos hoje que as mulheres com epilepsia de longa duração e em uso de medicações para o tratamento da epilepsia podem ter mais dificuldades para engravidar assim como para ter satisfação sexual com o seu companheiro. Neste trabalho, estamos estudando se as adolescentes já sofrem as mesmas alterações que as mulheres adultas, ou se elas ainda estão preservadas. Desta forma, poderemos evitar estas conseqüências na mulher adulta com epilepsia.

Para avaliar a função sexual, teremos que aplicar um questionário para a paciente. Se a paciente for menor, a mãe ou pai deve assinar este termo de consentimento. Mas, os pais devem saber, que tudo que sua filha responder não poderá ser contado para eles, ou seja, é sigiloso. Somente a paciente e a médica terão acesso a estas respostas.

Para avaliar se ela é fértil, teremos que fazer alguns exames em um dos ciclos do mês. Estes exames são de sangue e ultra-sonografia que serão repetidos $2 x$ no mês (entre o $2^{\circ}$ e o $3^{\circ}$ dia do ciclo menstrual e entre o $19^{\circ}$. e $24^{\circ}$. dia do ciclo menstrual). No $14^{\circ}$. dia, haverá avaliação ginecológica para análise do muco cervical que é uma forma de saber se sua filha tem ovulação normal. Com exceção do exame de sangue e análise do muco cervical, os demais não geram nenhuma dor ou dão algum desconforto.

\section{Desconfortos e riscos esperados:}

Os riscos associados com a coleta de sangue são desconforto e ferimento mínimos. Sempre que possível, colheremos o sangue no momento de algum procedimento clinicamente indicado, para que não haja necessidade de colher sangue somente para o propósito da pesquisa.

A análise do muco cervical é igual a um exame ginecológico, portanto um pouco desconfortável embora indolor.

\section{Benefícios que poderão ser obtidos:}

Você e a sua família irão receber uma informação importante sobre a sua fertilidade na sua idade e se necessário algumas alterações serão feitas quanto a sua medicação antiepiléptica para que você possa manter níveis de fertilidade normais, evitando as medicações que possam causar diminuição da ovulação. 


\section{ESCLARECIMENTOS DADOS PELO PESQUISADOR}

1. Você terá acesso, a qualquer tempo, às informações sobre procedimentos, riscos e benefícios relacionados à pesquisa, inclusive para dirimir eventuais dúvidas.

2. Você terá a liberdade de retirar seu consentimento a qualquer momento e de deixar de participar do estudo, sem que isto traga prejuízo à continuidade da assistência.

3. Todos os seus dados serão confidenciais e sua privacidade será respeitada.

4. Você terá disponibilidade de assistência no HC-FMUSP, por eventuais danos à saúde, decorrentes da pesquisa.

5. Você poderá ser indenizada por eventuais danos à saúde decorrentes da pesquisa.

Caso você tenha algum problema, poderá entrar em contato através dos telefones:

Dra. Sílvia de Vincentiis Fone: (011) 9799-0474 ou 3069-6518

\section{CONSENTIMENTO PÓS-ESCLARECIDO}

Declaro que, após convenientemente esclarecido pelo pesquisador e ter entendido o que me foi explicado, consinto em participar do presente Protocolo de Pesquisa.

São Paulo, de de 2007. 
Anexo II: Questionário para a avaliação de aspectos da sexualidade

Questionário para a avaliação de aspectos da sexualidade em adolescentes com epilepsia

\begin{tabular}{l|c}
\hline \multicolumn{1}{c|}{ INSTRUÇÃO } & Abipeme \\
\hline Analfabeto / Primário incompleto & 0 \\
Primário Completo / Ginasial Incompleto & 5 \\
Ginasial Completo / Colegial Incompleto & 10 \\
Colegial Completo / Superior Incompleto & 15 \\
Superior Completo & 21 \\
\hline
\end{tabular}

\begin{tabular}{l|c|c|c|c|c|c|c}
\hline \multicolumn{1}{c|}{ ITENS DE POSSE } & Não Tem & 1 & 2 & 3 & 4 & 5 & Mais de 6 \\
\hline Automóvel & 0 & 4 & 9 & 13 & 18 & 22 & 26 \\
Televisor em cores & 0 & 4 & 7 & 11 & 14 & 18 & 22 \\
Banheiro & 0 & 2 & 5 & 7 & 10 & 12 & 15 \\
Empregada mensalista & 0 & 5 & 11 & 16 & 21 & 26 & 32 \\
Rádio (excluindo do carro) & 0 & 2 & 3 & 5 & 6 & 8 & 9 \\
Máquinas de lavar roupa & 0 & 8 & 8 & 8 & 8 & 8 & 8 \\
Videocassete & 0 & 10 & 10 & 10 & 10 & 10 & 10 \\
Aspirador de pó & 0 & 6 & 6 & 6 & 6 & 6 & 6 \\
Geladeira comum ou com freezer & 0 & 7 & 7 & 7 & 7 & 7 & 7 \\
Computador & & & & & & & \\
Televisor branco e preto & & & & & & &
\end{tabular}

\begin{tabular}{c|c}
\hline CLASSES & CRITÉRIO Abipeme \\
\hline A & 89 ou mais \\
B & $59 / 88$ \\
C & $35 / 58$ \\
D & $20 / 34$ \\
E & $0 / 19$ \\
\hline
\end{tabular}


1) Idade da paciente:

2) Escolaridade:

3) Idade de início das crises epilépticas:

4) Data da última crise:

5) Freqüência das crises:

6) Classificação da epilepsia

-Classificação da crise epiléptica
( ) CPS
( ) $\mathrm{CPC}$
( ) TCG $2^{a}$ generalizada
( ) mioclonias
( ) ausência
( ) TCG $1^{\text {a }}$ generalizada
( ) outras

-Classificação da síndrome epiléptica
( ) Epilepsia parcial
( ) Epilepsia generalizada

-Classificação etiológica
( ) Idiopática
( ) Criptogênica
( ) Sintomática

7) Terapêutica atual e pregressa:

\begin{tabular}{|l|l|}
\hline Terapêutica Pregressa & \\
\hline Medicamentos & Dose \\
\hline & \\
\hline & \\
\hline & \\
\hline & \\
\hline & \\
\hline & \\
\hline
\end{tabular}




\begin{tabular}{|l|l|}
\hline Terapêutica Atual & \\
\hline Medicamentos & Dose \\
\hline & \\
\hline & \\
\hline
\end{tabular}

8) Menarca ( ) sim ( ) não Com quantos anos?

9) Ciclos menstruais ( )regulares ( )irregulares

Quantos dias de intervalo e fluxo?

10) Dismenorréia ( ) presente ( ) ausente

11)Idade da $1^{a}$ relação sexual Vida sexual ativa

( ) $\operatorname{sim}$ não ( ) ( se paciente virgem, pular para a questão 15).

12) Já engravidou alguma vez? ( ) sim ( ) não Número de filhos

13) As gestações foram planejadas? ( ) sim

Se não, estava usando algum método, e qual?

( ) não

14) Teve algum aborto? ( ) sim ( ) não Espontâneos ou provocados?

15) O uso de algum método contraceptivo foi orientado?( mesmo se paciente sem prática sexual no momento) ( ) sim ( ) não

16) Se sim, por quem? ( ) médico de seguimento da epilepsia ( neurologista/psiquiatra)

( ) ginecologista ( ) médico da família ( ) palestras na escola

( )outros

17) Houve orientação em consultas com o médico de seguimento da epilepsia quanto ao uso de camisinha e risco de aquisição de doenças como

SIDA e hepatite? ( ) sim ( ) não 
18) Sempre usa camisinha nas relações sexuais, mesmo que usando método contraceptivo outro? ( )sim ( ) não

19) Conhece contracepção de emergência? ( ) sim ( ) não Sabe usar? ( ) $\operatorname{sim} \quad($ ) não

20) Usa ácido fólico ( ) sim （） não

21) Se sim, sabe o motivo? ( ) sim ( ) não

22) Quem orientou o uso do ácido fólico? ( ) médico de seguimento da epilepsia ( )ginecologista ( ) médico da família

23) Foi orientada em consultas com médico da epilepsia sobre os riscos da gestação em mulheres com epilepsia?

( ) $\operatorname{sim}($ ) não

24) Foi orientada a procurar algum profissional de saúde para orientação sexual ou de contracepção? ( ) sim ( ) não

25) Procurou espontaneamente com esse objetivo? ( ) sim ( ) não ( ) nunca foi

26) Se procurou espontaneamente ou encaminhada, conseguiu atendimento? ( ) $\operatorname{sim}$ ( ) não

27) Se avaliada, conseguiu fazer o tratamento proposto? ( ) sim ( ) não Qual foi o tratamento e por que não conseguiu? 


\section{Módulo II}

28) Você se masturba? ( ) sim ( ) não

Se sim, qual a freqüência?

( ) todos os dias

( ) uma vez a cada 15 dias

( ) uma vez por mês

( ) esporadicamente

29) Você usa algum método anticoncepcional atualmente ( ) sim ( ) não Se usa, qual está usando?
( ) pílula
( ) injeção
( ) diafragma
( ) camisinha
( ) DIU
( ) interromper antes de gozar
( ) tabelinha
( ) "pílula do dia seguinte"

( ) geléia vaginal ( ) outros tipos de relação, como sexo oral.

30) Número de relações sexuais
( ) todos os dias
( ) uma vez por semana ou mais
( ) uma vez a cada 15 dias
( ) uma vez por mês
( ) de vez

em quando

( ) no momento sem vida sexual ativa

31) Número de parceiros no último ano ( ) nenhum $\quad\left(\begin{array}{lll}\text { ) } & \text { ( ) } 2\end{array}\right.$
( ) 3
( ) 4
( ) 5 parceiros ou mais

32) Você tem vontade de ter relação sexual? ( ) sim, sempre

( ) sim, na maior parte das vezes ( ) sim, mas poucas vezes

( )nunca.

33) Você tem prazer na relação sexual? ( ) sim, sempre （ ) sim, às vezes

( ) nunca.

34) Se atualmente você tem parceiro/namorado/marido/companheiro: Ele sabe que você tem epilepsia? ( ) sim （）não

35) No caso dele saber, você se sente amparada, cuidada por ele? ( )sim ( ) não 
Anexo III: Comparação entre comportamento e satisfação sexual com variáveis clínicas da epilepsia $(p<0,05)$

\begin{tabular}{c|c|c|c|c|c|c|c|c}
\hline & $\begin{array}{c}\text { Síndrome } \\
\text { epiléptica }\end{array}$ & $\begin{array}{c}\text { Duração da } \\
\text { epilepsia }\end{array}$ & $\begin{array}{c}\text { Freqüência } \\
\text { de crises }\end{array}$ & $\begin{array}{c}\text { Presença } \\
\text { de TCG }\end{array}$ & $\begin{array}{c}\text { Mono/ } \\
\text { politerapia }\end{array}$ & $\begin{array}{c}\text { Uso } \\
\text { VPA } \\
\text { atual }\end{array}$ & $\begin{array}{c}\text { Uso VPA } \\
\text { pregresso }\end{array}$ & $\begin{array}{c}\text { Controle } \\
\text { atual }\end{array}$ \\
\hline Libido & 0,16 & 0,56 & 0,91 & 0,26 & 0,91 & 0,56 & 0,34 & 0,18 \\
\hline $\mathbf{1}^{\text {a.relação }}$ & 0,68 & 0,69 & 0,53 & 0,81 & 0,34 & 0,86 & 0,82 & 0,67 \\
\hline Atividade & 0,09 & 0,51 & 0,50 & 0,60 & 0,38 & 0,21 & 0,40 & 0,25 \\
sexual & & & & & & & & \\
\hline
\end{tabular}

TCG: crise tônico-clônica; VPA: valproato 
Anexo IV: Dosagens hormonais

\begin{tabular}{|c|c|c|c|c|c|c|c|c|c|c|c|}
\hline & $\begin{array}{l}\text { Idade } \\
\text { (anos) }\end{array}$ & $\begin{array}{c}\text { T3 } \\
\text { (ng/dl) }\end{array}$ & $\begin{array}{c}\mathrm{T4} \\
\text { (ng/dl) }\end{array}$ & $\begin{array}{l}\text { T4 livre } \\
\text { (ng/dl) }\end{array}$ & $\begin{array}{c}\text { TSH } \\
(\mu \mathrm{U} / \mathrm{mL})\end{array}$ & $\begin{array}{l}\text { Prolactina } \\
\text { (ng/mL) }\end{array}$ & $\begin{array}{c}\text { Testosterona } \\
\text { (ng/dL) }\end{array}$ & $\begin{array}{l}\text { FSH f/l } \\
(\mathrm{IU} / \mathrm{L})\end{array}$ & $\begin{array}{l}\text { LH f/I } \\
(\mathrm{IU} / \mathrm{L})\end{array}$ & $\begin{array}{c}\text { Estradiol f/I } \\
\text { (pg/mL) }\end{array}$ & $\begin{array}{c}\text { Progesterona } \mathrm{f} / \mathrm{l} \\
(\mathrm{ng} / \mathrm{mL})\end{array}$ \\
\hline 1 & 16 & 126 & 10,5 & 1,21 & 1,1 & 5,9 & 46 & $5,8 / 2,0$ & $5,9 / 4,8$ & $43 / 159$ & $0,8 / 8,6$ \\
\hline 2 & 14 & 149 & 8,8 & 1,07 & 4,62 & 9,3 & 18 & $4,6 / 3,5$ & $2,5 / 1,5$ & $37 / 38$ & $0,4 / 0,4$ \\
\hline 3 & 16 & 107 & 7,6 & 0,96 & 2,28 & 12,6 & 47 & 4,0/--- & 5,8/--- & 34/--- & "' \\
\hline 4 & 19 & $--^{a}$ & --- & -- & --- & -- & --- & "--" & --- & --- & ---" \\
\hline 5 & 14 & 137 & 7,4 & 1,07 & 0,87 & 8,6 & 65 & 4,8/--- & 3,9/--- & 43/--- & 0,7/--- \\
\hline 6 & 12 & 143 & 11,5 & 0,99 & 1,72 & 9,7 & 34 & 6,0/---' & 3,9/--- & 17/--- & "' \\
\hline 7 & 14 & 152 & 11,2 & 1,22 & 3,31 & 13,6 & 86 & 2,4/---' & 5,0/--- & 64/--- & 2,0/---' \\
\hline
\end{tabular}

dl: decilitro; f/I: fase folicular/fase lútea; IU: unidades internacionais; L: litro; $\boldsymbol{\mu g}$ : microgramas; $\boldsymbol{\mu U}$ : microunidades; ml: mililitro; ng: nanogramas; pg: picogramas.

---.': impossibilidade de acesso venoso 
Anexo V: Aspecto ultra-sonográfico durante o ciclo menstrual

\begin{tabular}{|c|c|c|c|c|c|c|c|}
\hline & $\begin{array}{l}\text { Idade } \\
\text { (anos) }\end{array}$ & $\begin{array}{l}\text { Volume uterino } \\
\qquad\left(\mathrm{cm}^{3}\right)\end{array}$ & $\begin{array}{l}\text { Espessura } \\
\text { endométrio } \\
\text { (cm) }\end{array}$ & $\begin{array}{l}\text { Volume OD } \\
\qquad\left(\mathrm{cm}^{3}\right)\end{array}$ & $\begin{array}{l}\text { Volume OE } \\
\qquad\left(\mathrm{cm}^{3}\right)\end{array}$ & Morfologia OD & Morfologia OE \\
\hline 1 & 16 & $\begin{array}{c}42,5 / 35,8 / 30,9 / \\
35 / 61,9\end{array}$ & $\begin{array}{c}0,7 / 0,3 / 0,5 / \\
1,1 / 1,1\end{array}$ & $\begin{array}{c}7,7 / 7,0 / 6,0 / \\
14,7 / 29,0\end{array}$ & $\begin{array}{c}8,4 / 5,0 / 6,7 / \\
8,1 / 5,2\end{array}$ & $\begin{array}{c}\text { Normal/normal/normal } \\
\text { /formação cística/cisto } \\
\text { de corpo lúteo }\end{array}$ & $\begin{array}{c}\text { Normal/normal/normal/ } \\
\text { normal/normal }\end{array}$ \\
\hline 2 & 14 & $\begin{array}{c}29,2 / 24,7 / \\
29,2\end{array}$ & $\begin{array}{c}0,1 / 1,0 / \\
5,0\end{array}$ & $4,5 / 4,6 / 4,5$ & $5,2 / 4,8 / 5,1$ & $\begin{array}{c}\text { Cistos de padrão } \\
\text { folicular/normal/normal }\end{array}$ & $\begin{array}{c}\text { Cistos de padrão } \\
\text { folicular/normal/normal }\end{array}$ \\
\hline 3 & 16 & 43/--- & 0,4/--- & 10,9/--- & 33,0/--- & Normal/--- & $\begin{array}{c}\text { Formação cística (cisto } \\
\text { folicular) /--- }\end{array}$ \\
\hline 4 & 19 & 47/46,7/--- & $0,3 / 0,3 /---$ & 5,5/5,9/--- & $5,6 / 6,3 /---$ & Normal/normal/--- & Normal/normal/--- \\
\hline 5 & 14 & 66/41,5/--- & 0,7/0,5/--- & 12,0/9,3/--- & 7,7/7,5/--- & Normal/normal/--- & Normal/normal/--- \\
\hline
\end{tabular}

cm: centímetros; $\mathbf{c m}^{3}$ : centímetros cúbicos; OD: ovário direito; OE: ovário esquerdo 
Anexo VI: Parâmetros de função gonadal

\begin{tabular}{|c|c|c|c|c|c|c|}
\hline & $\begin{array}{c}\text { Ciclos menstruais } \\
\text { regulares }\end{array}$ & Dismenorréia & Níveis hormonais & USG & Gravidez & Função gonadal \\
\hline 1 & $\mathrm{P}$ & P & $\mathrm{N}$ & N & $A$ & $\mathrm{~N}$ \\
\hline 2 & $\mathrm{P}$ & " $\mathrm{P}$ & $--^{a}$ & Morfologia N & A & $\mathrm{CN}$ \\
\hline 3 & $A$ & A & --- & --- & A & $\mathrm{CA}$ \\
\hline 4 & $\mathrm{P}$ & P & --- & ---' & A & $\mathrm{CN}$ \\
\hline 5 & A & $A$ & --- & --- & $A$ & $\mathrm{CA}$ \\
\hline 6 & $\mathrm{P}$ & $P$ & $\mathrm{~N}$ & --- & A & $\mathrm{N}$ \\
\hline 7 & $\mathrm{P}$ & A & --- & ---' & A & 1 \\
\hline 8 & $\mathrm{P}$ & $P$ & --- & --- & A & $\mathrm{CN}$ \\
\hline 9 & --- & --- & --- & --- & $P$ & $\mathrm{~N}$ \\
\hline 10 & --- & --- & --- & --- & $P$ & $\mathrm{~N}$ \\
\hline 11 & $\mathrm{P}$ & $\mathrm{P}$ & $\mathrm{N}$ & ---' & A & $\mathrm{N}$ \\
\hline 12 & A & A & $\mathrm{N}$ & $\mathrm{N}$ & A & $\mathrm{N}$ \\
\hline 13 & $A$ & $P$ & --- & "--- & A & 1 \\
\hline 14 & --- & --- & --- & ---' & P & $\mathrm{N}$ \\
\hline 15 & $\mathrm{~A}$ & $P$ & NA & AN & A & AN \\
\hline 16 & $\mathrm{P}$ & P & $\mathrm{N}$ & AN & A & $\mathrm{N}$ \\
\hline 17 & $A$ & $\mathrm{P}$ & --- & --- & A & 1 \\
\hline 18 & $A$ & P & --- & --- & A & 1 \\
\hline 19 & --- & -"-- & --- & ---' & P & $\mathrm{N}$ \\
\hline 20 & --- & "--- & --- & "--- & $P$ & $\mathrm{~N}$ \\
\hline 21 & $\mathrm{P}$ & $A$ & --- & --- & A & 1 \\
\hline 22 & $\mathrm{P}$ & A & --- & ---- & A & 1 \\
\hline 23 & $P$ & P & --- & --- & A & $\mathrm{CN}$ \\
\hline 24 & A & $\mathrm{P}$ & --- & --- & A & $\mathrm{T}$ \\
\hline 25 & $\mathrm{~A}$ & $\mathrm{P}$ & $\mathrm{N}$ & Morfologia N & A & $\mathrm{N}$ \\
\hline 26 & $\mathrm{~A}$ & A & --- & --- & A & $\mathrm{CA}$ \\
\hline 27 & --- & ---" & --- & --- & P & $\mathrm{N}$ \\
\hline 28 & --- & --- & --- & ---' & P & $\mathrm{N}$ \\
\hline 29 & --- & --- & --- & --- & $P$ & $\mathrm{~N}$ \\
\hline 30 & $\mathrm{P}$ & $\mathrm{P}$ & --- & --- & A & $\mathrm{CN}$ \\
\hline 31 & --- & --- & --- & ---' & P & $\mathrm{N}$ \\
\hline 32 & --- & --- & --- & --- & $P$ & $\mathrm{~N}$ \\
\hline 33 & --- & --- & --- & ---' & P & $\mathrm{N}$ \\
\hline 34 & --- & --- & --- & --- & P & $\mathrm{N}$ \\
\hline 35 & --- & --- & --- & ---' & " $P$ & $\mathrm{~N}$ \\
\hline
\end{tabular}

A: ausente; AN: anormal; N: normal; CN: dados clínicos sugestivos de normalidade; CA: dados clínicos sugestivos de anormalidade; I: inconclusivo com dados conflitantes; P: presente; ${ }^{\text {a }}$, sem acesso venoso. 
Anexo VII: Comparação entre dados da menarca e ciclo menstrual com variáveis clínicas da epilepsia

$$
(p<0,05)
$$

\begin{tabular}{|c|c|c|c|c|c|c|c|c|}
\hline & $\begin{array}{l}\text { Síndrome } \\
\text { epiléptica }\end{array}$ & $\begin{array}{c}\text { Duração } \\
\text { da } \\
\text { epilepsia }\end{array}$ & $\begin{array}{l}\text { Freqüência } \\
\text { de crises }\end{array}$ & $\begin{array}{l}\text { Presença } \\
\text { TCG }\end{array}$ & $\begin{array}{c}\text { Mono/ } \\
\text { politerapia }\end{array}$ & $\begin{array}{l}\text { VPA } \\
\text { atual }\end{array}$ & $\begin{array}{c}\text { VPA } \\
\text { pregresso }\end{array}$ & $\begin{array}{c}\text { Controle } \\
\text { atual }\end{array}$ \\
\hline "Menarca & 0,46 & 0,70 & 0,009 & 0,87 & 0,08 & 0,94 & 0,04 & 0,27 \\
\hline Duração do fluxo & 0,26 & 0,42 & 0,39 & 0,11 & 0,84 & 0,17 & 0,26 & 0,86 \\
\hline $\begin{array}{l}\text { Regularidade do } \\
\text { ciclo }\end{array}$ & 0,30 & 0,06 & 0,88 & 0,20 & 0,20 & 0,23 & 0,49 & 0,88 \\
\hline $\begin{array}{l}\text { Intervalo entre } \\
\text { ciclos }\end{array}$ & 0,51 & 0,08 & 0,98 & 0,03 & 0,51 & 0,68 & 0,29 & 0,86 \\
\hline Dismenorréia & 0,92 & 0,22 & 0,63 & 0,55 & 0,55 & 0,57 & 0,04 & 0,48 \\
\hline Gestação & 0,48 & 0,67 & 0,44 & 0,15 & 0,15 & 0,28 & 0,89 & 0,95 \\
\hline Aborto & 0,50 & 0,18 & 0,71 & 0,31 & 0,18 & 0,31 & 0,18 & 0,69 \\
\hline
\end{tabular}

TCG: crise tônico-clônica generalizada; VPA: valproato; Negrito indica significância estatística 
